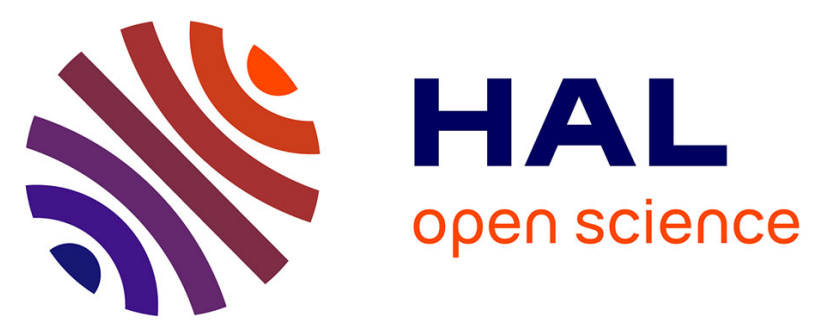

\title{
Detection and quantification of defect evolution at buried metal-oxide-polymer interface on rough substrate by local electrochemical impedance mapping
}

Thomas Sanchez, Ekaterina Kurchavova, Viacheslav Shkirskiy, Jolanta Swiatowska, Vincent Vivier, Polina Volovitch

\section{To cite this version:}

Thomas Sanchez, Ekaterina Kurchavova, Viacheslav Shkirskiy, Jolanta Swiatowska, Vincent Vivier, et al.. Detection and quantification of defect evolution at buried metal-oxide-polymer interface on rough substrate by local electrochemical impedance mapping. Electrochimica Acta, 2021, 388, pp.138467. 10.1016/j.electacta.2021.138467 . hal-03227692

\section{HAL Id: hal-03227692 \\ https://hal.science/hal-03227692}

Submitted on 17 May 2021

HAL is a multi-disciplinary open access archive for the deposit and dissemination of scientific research documents, whether they are published or not. The documents may come from teaching and research institutions in France or abroad, or from public or private research centers.
L'archive ouverte pluridisciplinaire HAL, est destinée au dépôt et à la diffusion de documents scientifiques de niveau recherche, publiés ou non, émanant des établissements d'enseignement et de recherche français ou étrangers, des laboratoires publics ou privés. 


\section{Detection and quantification of defect evolution at buried metal-oxide- polymer interface on rough substrate by local electrochemical impedance mapping} Thomas Sanchez ${ }^{1,{ }^{*}}$, Ekaterina Kurchavova ${ }^{1,2}$, Viacheslav Shkirskiy ${ }^{1}$, Jolanta Swiatowska ${ }^{1}$, Vincent Vivier ${ }^{2}$, Polina Volovitch ${ }^{1, *}$

${ }^{1}$ Chimie ParisTech-CNRS, PSL Research University, Institut de Recherche de Chimie Paris (IRCP), 11 rue Pierre et Marie Curie, 75005 Paris, France

${ }^{2}$ Laboratoire Interfaces et Systèmes Electrochimiques, Sorbonne Université, 4 place Jussieu 75252 Paris Cedex 05

\section{Abstract}

The role of the local nanometric thinning in trivalent chromium conversion coating for the electrochemical stability of buried metal-oxide-model epoxy interface formed on a rough (arithmetic average roughness parameter $R_{a}=5 \mu \mathrm{m}$ ) electrodeposited substrate is presented. For different morphologies and sizes of thinned zones, the buried interface stability was tested in ACDC-AC procedure. Local oxide thinning at zones of $<0.25 \mathrm{~mm}^{2}$ was successfully detected by local electrochemical impedance mapping (LEIM). LEIM was able to measure in situ the interface degradation kinetics and distinguish the defects for which the interface underwent severe degradation from others in both terms of defect size and underpaint reactivity. The evolution of LEIM maps was in good agreement with the optical observations from 3D image reconstruction performed ex situ, thus validating quantitative LEIM as a tool for the local degradation quantification of buried interfaces. Based on the evolution of cathodic charge, LEIM and ex situ optical microscopy, it was demonstrated that the zone with local thinning of conversion coating on the rough substrates needs to reach some critical size to affect significantly the underpaint reactivity. Otherwise, the surface inhomogeneity related to the initial roughness hinders the effect of the local oxide thinning.

\section{Highlights}

- Controlled local oxide thinning on rough $\left(R_{a}=5 \mu \mathrm{m}\right)$ substrate prior to painting

- Oxide thinning on areas $<\mathrm{mm}^{2}$ did not affect the electrochemical response

- Nanometric oxide thinning on areas of $\sim \mathrm{mm}^{2}$ and more affected underpaint stability

- Reactivity front advancement from underpaint defect was quantified in situ by LEIM

- LEIM discriminated degradation modes confirmed ex situ by optical microscopy 
1 Keywords: Local electrochemical impedance spectroscopy, conversion coating, buried interfaces, 2 material degradation

3

4

5

6 


\section{Introduction}

Polymer coated metals are among the most used combinations in hybrid materials and composite materials designed for multiple applications, from structural materials in building, automotive, aerospace industries [1,2,3] to electronic devices [4] and medical disposals [5]. In many cases these assemblies arise from the necessity to combine mechanical strength of metallic substrates with improved life time, offered by protective polymer coatings. The reliability and the lifetime of these assemblies strongly depend on the stability of the interfaces between the metal substrates and polymers. To improve the corrosion resistance of the substrate metal and the polymer adhesion in such assemblies, the metallic surface is often passivated with the formation of a thin layer of conversion coating (oxide [6], phosphate [7], titanate [8] etc.). The metal-oxidepolymer interfaces degrade under an interplay of multiple constrains resulting from their fabrication and service conditions (residual or applied mechanical stresses, presence of pollutants at the interface or in the atmosphere, humidity, temperature, UV radiation etc.) and are particularly sensitive to the formation of liquid phase which can lead to polymer permeability, swelling or blistering, water adsorption at the interface with degradation of the oxide layer or even corrosion of the underneath metal $[9,10,11]$.

Although multiple accelerated tests have being used in different applications for stability verification of metal-oxide-polymer systems (continuous salt spray test, cyclic climatic tests (VDA [12], pressure cooker test (PC test [13]) common in electronic devices, immersion test to reveal blistering [14,15], etc.), these tests only permit the observation of the initial and final state but do not allow to survey the system evolution with time. As a result, despite their necessity, accelerated tests remain long, expensive and insufficient to access degradation mechanisms. Moreover, they could irreversibly modify these mechanisms. For these reasons, the development of in situ methods able to understand the evolution of metal-oxide-polymer interfaces during degradation attracts more and more attention $[11,16,17,18,19,20]$.

In situ chemical analysis of the evolution of buried metal-oxide-polymer interfaces is usually approached using model systems formed by thin layer deposition [21].

To access the overall (average over the whole sample) stability of painted systems, electrochemical techniques (open circuit potential (OCP), linear polarization resistance, electrochemical noise and electrochemical impedance spectroscopy (EIS)) can be applied in situ to complex systems, including industrial coatings made of thick layers $[22,20,23]$ and offer rapid quantitative or semi-quantitative evaluation of the system using simple instruments. In particular, EIS was used to describe the non-homogeneities of painted systems, the distribution of polymer coating properties [24], to survey degraded areas at metal-oxide-polymer interface [25] and water uptake in the polymer coating $[26,27]$.

Although the EIS technique allows to describe some heterogeneous processes occurring during ageing of painted systems, it can detect the existence of such defects but cannot assign 
1 them to certain points on the examined surface. The development of local electrochemical

2 techniques is therefore necessary. Several techniques were previously used to describe local

3 degradation of polymer coated systems. Scanning Kelvin probe (SKP) detects the differences in

4 corrosion potential at different locations of the buried interface $[28,29,30]$. Scanning vibrating

5 electrode techniques (SVET) measures the local currents, which can be helpful to characterize

6 defects in coating but cannot overcome the inherent difficulty in measuring currents underneath

7 high resistance coatings [31,32]. Local electrochemical impedance spectroscopy and mapping

8 (LEIS and LEIM) [33,34,35,36,37,38] are becoming widespread techniques to study buried

9 interfaces for the systems in which the polymer does not have initial defects $[39,40,41]$. SVET and

10 LEIS measure both the local current density, for the former case, the DC component is measured,

11 whereas for the later, the AC component at a selected frequency can be obtained. It thus allows

12 to select which property (charge transfer, capacitance, diffusion, adsorption, etc.) to be

13 investigated.

Despite the increasing number of works applying LEIS and LEIM for the description of degradation at metal-oxide-polymer interfaces, very small number of them treat the evolution of the system in a quantitative way $[35,36]$ and to our knowledge no studies were devoted to the verification of the analytical limits of LEIS and LEIM for the detection of the active areas under intact polymer. Moreover, the theoretical limits of LEIS and LEIM techniques are elaborated for flat substrates, while many industrial substrates are electrodeposited alloys, therefore rough. The roughness is often described by the arithmetic average roughness parameter, $R_{a}$, defined as the arithmetic average value of filtered roughness profile determined from the absolute value of deviations about the center line within the evaluation length. For instance, $R_{a}$ for the electrodeposited $\mathrm{Zn}$-based coatings can be in order of 2 to $5 \mu \mathrm{m}$ while the distance between the tallest peak and the deepest valley can be more than $10 \mu \mathrm{m}$. Such morphological inhomogeneity of the substrate can affect distribution of conversion coating, thickness homogeneity of the polymer coating and electrochemical current distribution above the surface, which should be detected by LEIS and LEIM techniques. The later can alter the capacity of the techniques to describe local reactivity.

The understanding of the analytical limits of the LEIS and LEIM techniques to detect and to quantify the defects at buried metal-oxide-polymer interfaces on rough substrates can be of high importance for the development of new conversion coatings, which is an emerging technology because of the European directives prohibiting the use of hexavalent chromium based conversion coatings [42,43].

The main objective of the present work is to propose a methodology for such an evaluation for electrodeposited Zn-alloy substrate with a $\mathrm{Cr}$ (III) conversion coating and an epoxy polymer paint. The proposed approach is based on the interplay of the concepts developed in our previous works, namely: 
1) a quantitative description of the deadhesion (delamination) advancement from a defect in the polymer coating at metal-polymer interface using LEIM [36]

2) an application of a model epoxy - based coating which allows LEIM measurements underneath without a preliminary defect formation and helps to mimic the behavior of buried interface and distinguish conversion coating with and without defects [41]

3) a methodology able to produce a controlled local nanometer thinning of conversion coating without affecting the roughness of the substrate [44].

The choice of the studied system was made on the basis of the large application Zn-based metallic coatings used for sacrificial protection of steel [45] and $\mathrm{Cr}(\mathrm{III})$ based conversion coatings as an alternative for the replacement of hexavalent $\mathrm{Cr}$ based coatings [46,47]; whereas epoxy based polymers are among the most used in packaging applications.

By combining LEIM, EIS and high-resolution 3D optical microscopy, the question about the minimal size/distribution of the defect in conversion coating which evolution can be detected and quantified by LEIS/LEIM with the used experimental set up is addressed. 


\section{Experimental}

\subsection{Materials}

\subsubsection{Substrate}

Mild steel with electrodeposited $\mathrm{Zn}$-based metallic coating and $\mathrm{Cr}$ (III)-based conversion coating, produced as described in [41], was used as the substrate. The coating consisted of approximately $18 \pm 2 \mu \mathrm{m}$ thick layer of electrodeposited $\mathrm{Zn}-14$ at. \% Ni intermetallic $\left(\mathrm{Zn}_{21} \mathrm{Ni}_{5}\right)$ and trivalent chromium conversion coating layer of $\sim 30 \pm 5 \mathrm{~nm}$ thickness. The composition of the intact conversion layer determined by XPS is presented in Table 1 . Six coupons of $3 \times 3 \mathrm{~cm}^{2}$ were cut from the central part of each sample to avoid the edge effects possible in electrodeposition process. The coupons coming from the same plate are considered in the following as the same batch.

\section{$<$ Table 1>}

The values of the arithmetical mean deviation roughness parameter, $R_{a}$ and the difference between the highest (peak) and the lowest (valley) position on the studied surfaces $R_{z}$ were measured by a confocal optical microscopy. The measured values of $R_{a}=5 \pm 0.5 \mu$ m were similar for all the studied samples. The $R_{z}$ values varied in the range of the tenth of micrometers. These results are coherent with the expected roughness of electrodeposited $\mathrm{Zn}-\mathrm{Ni}$ alloys. Prior to the generation of the model defects and polymer coating, the samples were stored in a desiccator.

\subsubsection{Model defects generation procedure, morphology and chemical composition}

In order to produce model craters on the surface, sputtering with ions of the conversion coating was performed using either Glow Discharge Optical Emission Spectroscopy (GD-OES) or Time of Flight Secondary Ion Mass Spectrometry (ToF-SIMS) equipment. The sputtering parameters were chosen in a way that for both types of generated craters the conversion layer was thinned but still present all over the crater area and was not chemically modified. The procedure is described in detail in [44].

Briefly, to determine the erosion duration, four elemental in-depth profiles were performed in different locations for each batch prior to the generation of the crater in the conversion coating. XPS demonstrated that $\mathrm{Ni}$ is not incorporated in the conversion coating (Table 1, see also [44]). At the same time $\mathrm{Ni}$ is present in the metallic substrate. Thus, $\mathrm{Ni}$ signal evolution was used as a marker in order to define the interface between the metallic substrate and the conversion coating. The interface was assigned to a point with $50 \%$ of the maximum $\mathrm{Ni}$ signal in the profile. The sputtering time necessary to reach the interface, $t_{s}$, was thus detected for each batch and the craters were generated using the sputtering time of $0.8 \times t_{s}$. It was assumed that $80 \%$ of the initial thickness is eroded in such a procedure (see [44] for details). 
For the crater generation by GD-OES, the argon ( $\mathrm{Ar}$ ) plasma pressure was set at $650 \mathrm{~Pa}$ and the power at $8 \mathrm{~W}$. For the crater generation by ToF-SIMS, an oxygen ion source $\left(\mathrm{O}_{2}{ }^{-}\right)$was used at $2 \mathrm{keV}$ acceleration voltage delivering $100 \mathrm{nA}$ of target current over a $30 \times 30 \mu \mathrm{m}^{2}$ area; thus, avoiding $\mathrm{Cs}^{-}$implantation in the conversion coating. For the same reason, the crater generation was performed without using the $\mathrm{Bi}^{+}$primary ion gun. In both cases, the chemical composition in the crater was very close to the composition of the initial conversion layer on the intact samples (see Table 1 which compares the elemental composition of the conversion coating obtained by XPS in the intact zone and inside the crater of $4 \mathrm{~mm}$ in diameter). Topographic analysis of the surfaces inside and outside the sputtered areas showed no significant effect of nanometric conversion coating sputtering on the $R_{\mathrm{a}}$ and $R_{\mathrm{Z}}$ values $\left(R_{\mathrm{a}} \sim 5 \mu \mathrm{m}\right.$ and $\left.R_{\mathrm{Z}} \sim 10 \mu \mathrm{m}\right)$.

The homogeneity of the oxide thickness distribution in the sputtered craters was in detail characterized using the methodology described in [44]. The thickness variation between different locations on the same sample was not more than $30 \%$. Briefly, the local depth profiles were obtained in multiple locations inside and outside the crater by PHI 710Xi Auger nanoprobe, equipped with a cylindrical mirror analyzer (CMA) mounted coaxially with respect to the electron column. The take-off angle of the analyzed Auger electrons was below $30^{\circ}$ from the primary electron beam, which minimized the shadowing effect. As in [44], the results demonstrated homogeneous erosion inside GD OES craters and shadowing effects existed in the craters formed by ToF SIMS sputtering. The latter can lead to the "effective" area which is smaller than targeted zone in case of the defects produced by ToF SIMS.

\subsubsection{Types of defects}

Six coupons were cut from each batch. Two of them were used as reference samples (without defect) and on four others four different types of model defects were produced. Two types of the model defects and their characteristics are illustrated in Fig. 1b and $\mathbf{1 c}$. The samples produced by GD-OES presented a single cylindrical crater in conversion coating. The crater diameter, $d$, was 2 or $4 \mathrm{~mm}$. The overall linear dimension $D$ of the defect zone containing a single crater is defined by the crater diameter, hence is defined here as $D=d$ (see Figs. 1a and 1 $\mathbf{b}$ ). The defect zone produced by ToF-SIMS is more complex. It consisted of a grid of $N \times N$ square craters each of which has a side $d$ (see Fig. 1c), leading to an inhomogeneous defect zone with a total linear dimension $\mathrm{D}(\mathrm{D}<1 \mathrm{~mm})$ as sketched in Figure 1c.

<Fig. 1>

3D microscopy images of the formed craters are shown in Fig. 2. Despite the initial roughness of the substrate and the fact that only the conversion coating layer is damaged [44], the crater is clearly distinguishable in reflection mode (Fig. 2, photos). As it can be expected from a nanometric thinning, the profilometry above the sample shows that the surface roughness inside and outside the crater is the same and corresponds to the roughness of the electrodeposited Zn alloy (Fig. 2, 37 profiles). 
<Fig. 2>

The targeted as well as the measured by optical microscopy dimensions of the five types of the samples studied in this work are summarized in Table 2.

$<$ Table 2>

Considering that the initial roughness may vary from one batch to the other, all the experiments discussed below were repeated on 6 different batches. For consistency reasons, in the results sections the effect of different types of the defects on the observed electrochemical behavior and optical appearance are systematically illustrated for the samples produced inside the same batch. One should however note that for all the batches the observed tendencies in the electrochemical responses were similar.

\subsubsection{Polymer coating}

Prior to electrochemical testing, the samples with and without model defect were coated by the model epoxy polymer developed in [41]. It consisted of DiGlycidyl Ether of Bisphenol-A prepolymer and TriEthylene TetrAmine hardener (DGEBA-TETA) used in (1:1) ratio. For viscosity requirements, the preparation was diluted in $3 \mathrm{~mL}$ of ethanol (analytical grade) for $4 \mathrm{~g}$ of mixture. Prior the deposition step, the preparation was placed in a hermetic beaker and mixed at $300 \mathrm{rpm}$ for 20 minutes then left to stand for 15 minutes in order to remove air bubbles. Just before the coating application, the surface of the substrate was rinsed with absolute ethanol to improve wettability.

The polymer was deposited by spin coating using a POLOS SP15 spin-coater. Once the sample was placed and held in the spin-coater, the resin was poured in large excess and spread on the whole surface, the spin coating was performed twice with a $15 \mathrm{~s}$ relaxation time in between with the following parameters: 3000 RPM rotation speed (achieved by 500 RPM/s linear acceleration) for $35 \mathrm{~s}$. After the spin-coating step, the samples were cured at $50 \pm 5{ }^{\circ} \mathrm{C}$ for $14-16 \mathrm{~h}$. This procedure allows controlled coating thickness on a flat substrate at ca. $10 \pm 1 \mu \mathrm{m}$ to be obtained [41]. Moreover, the roughness of the substrate in the present work is comparable with the expected polymer thickness. Taking into account the levelling effect of the paint, one could expect hence several $\mu \mathrm{m}$ variation of the polymer thickness between the surface hills and valleys on the rough electrodeposited substrate.

The samples were stored in a desiccator between the coating application and the degradation test. Degradation tests were performed in the following week. 


\subsection{Electrochemical setup and degradation procedure}

Electrochemical experiments were performed using a Solartron Modulab potentiostat with the ECS software interface in a home-made electrochemical cell placed in a Faraday cage. The cell used a silver/silver-chloride $(\mathrm{Ag} / \mathrm{AgCl})$ reference electrode $(\mathrm{RE})$, the coated sample (with $2 \mathrm{~cm}$ in diameter exposed zone delimited by an O-ring) as a working electrode (WE) and a platinum wire, shaped as a circle of $3 \mathrm{~cm}$ in diameter centered above the exposed zone, as the counter electrode (CE). This setup configuration was used to guarantee symmetrical distribution of current lines, thus minimizing artefact in EIS measurements. All the experiments were performed at room temperature $\left(25 \pm 2^{\circ} \mathrm{C}\right)$ in $25 \mathrm{~mL}$ of $0.01 \mathrm{M} \mathrm{NaCl}$ containing $1 \mathrm{wt}$. \% of phenolphthalein as a $\mathrm{pH}$ indicator.

The degradation procedure was based on our previous work [41]. Briefly, all the coated samples were firstly immersed for 1 hour to reach a stable value of open circuit potential (OCP). After the first EIS and LEIM measurement, seven AC-DC-AC cycles were performed. Each cycle, schematically presented in Fig. 3, consisted of 15 minutes of cathodic polarization at -1.5 $\mathrm{V} / \mathrm{Ag} / \mathrm{AgCl}$ followed by a $15 \mathrm{~min}$ immersion (relaxation) at OCP and a remaining period of $30 \mathrm{~min}$ for EIS and LEIM measurements. The total duration of each test was hence 8.5 hours. After the cycling and before ex situ characterizations, the sample was rinsed with milli-Q water and dried with compressed air.

\section{<Fig.3>}

\subsection{Electrochemical impedance}

EIS spectra were carried out at the OCP from $100 \mathrm{kHz}$ to $0.1 \mathrm{~Hz}$ with 6 points per frequency decade and $20 \mathrm{mV}_{\mathrm{RMS}}$ sinewave signal.

For LEIM, the setup used in $[40,41]$ was adopted. The local probe consisted of two Ag wires (each of $150 \mu \mathrm{m}$ in diameter) sealed in twin-capillaries and separated by $400 \mu \mathrm{m}$ between the wire centers. $\mathrm{AgCl}$ deposit was obtained by five minutes potentiostatic polarization at 0.4 $\mathrm{V} / \mathrm{Ag} / \mathrm{AgCl}$ in $0.5 \mathrm{M} \mathrm{NaCl}$ solution. The quality and the stability of the deposit were verified by EIS measurements of the $\mathrm{Ag} / \mathrm{AgCl}$ electrodes in $0.01 \mathrm{M} \mathrm{NaCl}$ solution after different times between 5 $\min$ and $10 \mathrm{~h}$. The electrodes were placed perpendicular to the surface of the sample at a probe to sample distance of $100 \pm 25 \mu \mathrm{m}$.

A home-made setup using Solartron Modulab software with auxiliary input and a 3-axis stepper motor-controlled by Sensolytics was used for LEIM data acquisition.

The mapping was made with the potential oscillation of $50 \mathrm{mV}_{\mathrm{RMS}}$ at a $400 \mathrm{~Hz}$ frequency. $6 \mathrm{x}$ $6 \mathrm{~mm}^{2}, 4,5 \times 4,5 \mathrm{~mm}^{2}$, and $3 \times 3 \mathrm{~mm}^{2}$ maps were acquired by measuring the local impedance on series of $31 \times 31$ points spaced by $200 \mu \mathrm{m}, 150 \mu \mathrm{m}$, and $100 \mu \mathrm{m}$, respectively, depending on the defect size.

Each mapping was performed in approximately $20 \mathrm{~min}$. 
1 The size evolution of the active zone was estimated from the evolution of the distance between

2 the extrema of the local impedance gradient mapping [48]. The gradient maps of the local impedance were calculated and represented with an in-lab developed Python script [36].

\subsection{Optical characterization}

In situ time lapse microscopy (TLM) using an HD USB microscope with 2 MP CMOS detector and a $4000 \mathrm{~K}$ white LED enlightenment was set up in the electrochemical cell. This allowed to complete the electrochemical measurement with a monitoring of a possible surface evolution, the local solution coloration (pink color in phenolphthalein due to the cathodic $\mathrm{pH}$ increase) and the hydrogen evolution.

The objective to surface distance was set to $4 \mathrm{~cm}$ for a magnification of $\times 80$. The instrumental acquisition parameters and surface characteristics leaded to an approximately $100 \mu \mathrm{m}^{2}$ pixel size. A picture was taken every minute during immersion and during cathodic polarization in the ACDC-AC test.

Ex situ optical characterization of the samples was performed using a Keyence VHX-5000 microscope equipped with the $\mathrm{VH}-\mathrm{Z} 500 \mathrm{~T}$ objective, allowing magnification from $\times 500$ to $\times 5000$. With $\times 500$ magnification, the area of view was of $610 \times 457 \mu \mathrm{m}^{2}$ for a $2000 \times 1600$ pixels ${ }^{2}$ image. For wider area image acquisition, an image stitching was performed [49]. Thanks to its short depth of field $(<0.5 \mu \mathrm{m})$, multiple images with different objective-to-sample distances were taken, allowing the reconstruction of a 3D image of the surface [50].

The wide area observation of the sample's surfaces consisted of the stitching of 100 (10 x 10) 3D-composition at 500x magnification over $5.0 \times 4.1 \mathrm{~mm}^{2}$. Each 3D-composition was computed from 50 images over 50 microns in height. High resolution images were obtained by 3Dcomposition with 2000x magnification. The height range of the composition was selected in order to be able to focus on both, the top surface of the polymer coating using grazing light or on the substrate below the polymer coating

The roughness parameters $R_{\mathrm{z}}$ and $R_{\mathrm{a}}$ inside and outside the craters were obtained from the Keyence VHX-5000 microscope measurements of the height of each focused pixel, which allowed a topographic measurement of the surface. The height cartography was converted to an 8-bit grey nuance image. Topography and roughness parameters were extracted and calculated with the Gwyddion software v2.50 [51]. 


\section{Results}

\subsection{In situ optical surface evolution during cycling}

The Fig. 4 shows the in situ images taken during the cathodic polarization step of the first and the fourth cycle of the samples with the defects $A, B$ and $C$ with the initial size $D_{0}=3.8, D_{0}=1.8$ and $D_{0}=0.8 \mathrm{~mm}$, respectively.

$<$ Fig.4>

The localization of the initial defect in the conversion coating is highlighted in Fig. 4 by the black circle on the images taken during the first cycle (left column in the figure). The defect $A\left(D_{0}\right.$ $=3.8 \mathrm{~mm}$ ) can be easily identified from the first cycle: a dark circular shape in the center of the black circle is visible. The defect $\mathrm{B}\left(D_{0}=1.8 \mathrm{~mm}\right)$ can also be detected by its circular shape and the color which is lighter than the color on the residual surface. On the contrary, the defect $C\left(D_{0}=\right.$ $0.8 \mathrm{~mm}$ ) is not visible through the coating at this magnification. Similarly, the presence of the smallest defect $D$ (not shown) was not visible in optical observations.

After four cathodic polarization cycles (right column in the figure) all samples show some hydrogen evolution, proof of the cathodic reactivity, revealed by little bubbles dispersed on the surface of the three samples. However, only for the sample $A$, the hydrogen evolution is clearly more pronounced in the vicinity of the defect while it seems to be homogeneously distributed over all the surface of the samples B and C. The intact sample and the sample D with the smallest defect are not shown. However, their appearance and evolution during cycling was similar to the evolution observed for the sample $C$.

\subsection{Open circuit potential evolution and charge under cathodic polarization}

After one hour of immersion, all the samples showed a stable open circuit potential (OCP). In the presence of the defect, the OCP was 30 to $60 \mathrm{mV}$ more cathodic that the OCP of the undamaged sample (about $-0.66 \pm 0.02 \mathrm{~V}$ vs. $\mathrm{Ag} / \mathrm{AgCl}$ ).

In Fig. 5a the examples of the OCP evolution during the relaxation step after cathodic polarization for the first, fourth and seventh AC-DC-AC cycles are presented for samples with millimeter size defects $A\left(D_{0}=3.8 \mathrm{~mm}\right)$ and $B\left(D_{0}=1.8 \mathrm{~mm}\right)$ and for the sample with intact conversion coating. In all cases, after polarization the OCP tends to recover to its original values but the relaxation time increases with cycling. It should be noted that we were obliged to mix the electrolyte prior to LEIM measurement due to the formation of hydrogen bubbles on the surface during cathodic cycle in the case of the big defect. The detachment of bubbles can be responsible for the OCP instability for the sample A, as shown in Fig. $\mathbf{5 a .}$

\section{$<$ Fig.5>}


Fig. $\mathbf{5 b}$ shows the examples of cathodic current evolution during cathodic polarization for the first, the fourth and the seventh cycles for the same samples A and B with millimeter size defects and for the sample with an intact conversion coating. For the intact system, the surface appears to be initially more active than during the polarization, because the cathodic current slightly decreases in the first seconds of polarization and reaches a stable value in approximately 100 seconds. Then, the current increases gradually with cycling, indicating either gradual increase of the overall cathodic reactivity at the interface or the increase of the size of the active areas. The behavior was similar for the small defect grids $C$ and $D$ of all different batches.

The evolution of the cathodic current at the first, third, fifth and seventh cycles on samples $A$ $\left(D_{0}=3.8 \mathrm{~mm}\right)$ and $\mathrm{B}\left(D_{0}=1.8 \mathrm{~mm}\right)$ show a different behavior. During the three first cycles, the current decreases with polarization time as well but without reaching a stable value. From the $5^{\text {th }}$ cycle the shape of the current curve of the sample B changes, reflecting no initial current peak but in contrast less current in the first seconds of polarization and the following current increase and rapid stabilization. For the sample $A$ there is no change in the shape of the curves even if after several cycles the initial current peak decreases. From the $5^{\text {th }}$ cycle, the cathodic current achieved at the end of polarization decreases with cycling for the sample B while it still grows for the sample A.

One should note that even though the absolute values of the cathodic currents measured in different batches were slightly different, the tendencies illustrated in Fig. $\mathbf{5}$ were observed for all batches.

The evolution of the total cathodic charge accumulated during cathodic polarization with cycling is presented in Fig. 6 a for the samples $A, B, C$ and $D\left(D_{0}=3.8,1.8,0.8\right.$ and 0.3 respectively) taken from the same batch 1 . The increase in the size of the defect results in the higher exchanged charge, which is consistent with the two order of magnitude increase of the cathodic current in the presence of the millimeter size defect in conversion coating observed in Fig. 4. For the two biggest defects generated by GD-OES $\left(D_{0}=1.8 \mathrm{~mm}\right.$ and $D_{0}=3.8 \mathrm{~mm}$ ), a similar behavior is observed: the total charge increases for the three first cycles, then it stabilizes and then decreases in the last step (Fig. 6a). The cathodic charge on the sample $C\left(D_{0}=0.8 \mathrm{~mm}\right)$ continuously decreases with cycling, reaching $2 \times 10^{-3} \mathrm{C}$. For the sample $D$ with the smallest defect $\left(D_{0}=0.3 \mathrm{~mm}\right)$, the cathodic charge during potentiostatic polarization step continuously increases with cycling, reaching the same values than the sample $C$. The values for the reference sample with the intact conversion coating being very close to the values, obtained for the sample $D$, the exchanged charge evolution for the intact sample from the same batch (intact 1 ) is shown separately in Fig. $6 \mathrm{~b}$.

\section{<Fig.6>}

Additionally, Fig. $\mathbf{6 b}$ illustrates the reproducibility of the exchanged charge measurement between two different batches of samples. The exchanged cathodic charge varies within a factor of 3 for the samples without initial defect in conversion coating (intact (1) and intact (2)). The 
latter could be attributed to the impact of the local variation of the micrometric substrate roughness on the polymer thickness. Taking into account this variation for intact samples, the difference between the intact sample and the sample $D$ with the defect area less than $0.3 \mathrm{~mm}^{2}$ seems to be statistically irrelevant. Similarly, the cathodic reactivity (exchanged charge) of the sample $C$ after 4-5 cycles can be considered as similar to the cathodic activity of an intact sample.

Fig. $6 c$ shows the evolution of the total charge, passed during cathodic polarization step of the AC/DC cycle, as a function of the estimated surface of the underpaint defect (detailed in 3.4) for the first, fourth and seventh cycles. As it could be expected, the total charge passed through the sample with a defect increases with the defect area. However, the relation between the defect area and the total charge clearly differs from the linear behavior, expected from the integrated Cottrell equation (known as Anson equation).

\subsection{Electrochemical impedance spectroscopy}

The electrochemical impedance spectra at OCP of the samples A, B, C, D and I in the Bode representation (impedance modulus $|Z|$ and phase angle in function of frequency $\omega$ ) at the first, fourth and seventh cycles are presented in Fig. 7.

<Fig.7>

All spectra show a similar response involving two time-constants, reflecting two main contributions, namely the polymer coating in the $\mathrm{HF}$ domain (above $10^{4} \mathrm{~Hz}$ ), and the metal-oxideelectrolyte interface in the LF domain (below $10^{3} \mathrm{~Hz}$ ). The polarization cycles show to a gradual decrease in the modulus of the impedance in the lower frequency domain, which is consistent with the degradation of the painted system.

After the fourth cycle, the impedance spectra do not vary and show a similar trend whatever the size of the defect. Such a behavior is ascribed to the small dimension of the surface fraction of the defect area with respect to the total analyzed surface: $3.3 \%, 0.8 \%, 0.06 \%$ and $0.01 \%$ for defect $A, B, C$ and $D$, respectively. Previously, theoretical estimations of the effect of defect sizes in the polymer coating on the impedance response [52] showed that below approximately $0.01 \%$ fraction area of the defect on the surface, an accurate description becomes difficult.

The capacitance of the interface of the system can be obtained from the extrapolation of the complex capacitance plot, $C^{*}$, to infinite frequency using [53]:

$$
C^{*}(\omega)=\frac{1}{j \omega \times\left(Z(\omega)-R_{e}\right)}
$$

where $R_{e}$ is the electrolyte resistance. The interest of this approach is that it does not require any assumption for a specific model (which could be ambiguous for coated systems) and however allows data fitting [54]. The method is based on the fact that the constant-phase element behavior approaches a pure capacitive response at high frequencies. It allows the capacitance of the interface to be obtained from the extrapolation of the capacitance diagram in the high frequency domain, which in turn, allows the determination of the coating thickness as shown in 
detail in [53]. Additionally, minute change in the capacitance can be linked either to the solvent uptake, but also to the evolution of the defect. The estimation of global capacitance only provides an average value across the polymer layer. It provides a back-of-the-envelope calculation with the description of the localized effects presented in the following sections.

The capacitances calculated with the Eq. (1) for the systems with and without millimeter size defects in the conversion layer at different steps of ageing cycling varied between 0.8 and $2.9 \mathrm{nF}$ $\mathrm{cm}^{-2}$ (see Fig. 8).

<Fig.8>

Dielectric constant of dry epoxy resins varies in the range 2.5-6, however humidity is known strongly to increase permeability. Previously, dielectric constants as high as 10 to 15 were reported for the organic coating immersed in aqueous solutions [53]. Considering epoxy coating dielectric constant of 10, the capacitance values lead to the epoxy thickness between 3 and 10 $\mu \mathrm{m}$. Such values are indeed possible since the polymer levels the initially rough surface with $R_{a}$ of $5 \mu \mathrm{m}$ and $R_{\mathrm{z}}$ of $10 \mu \mathrm{m}$. It is important to note that the capacitance evolution with cycling shown in Fig. 8 demonstrates higher variation between the absolute values obtained for different samples without the defect (filled forms of different shape) than between the samples with and without defect (filled and open forms of the same shape). This was true even for the samples with the biggest defect, for which cathodic reactivity was clearly higher than for all other samples. The latter makes questionable the applicability of capacitance calculation for understanding the degradation of these systems. For samples with $4 \mathrm{~mm}$ defect (shown by open circle and open square symbols in Fig. 8), the capacitance seemed to increase with cycling by about 2-3 \% of its absolute value. However, for the samples without the defect or with defect smaller than $3.8 \mathrm{~mm}$ in diameter, no clear tendency could be drawn from the results.

Thus, the measured by EIS signal is mainly affected by the initial inhomogeneity of the polymer coating and cannot really distinguish the contribution of the localized nanometric thinning of conversion coating at the metal-polymer interface. The local evolution of the defected areas needs hence to be surveyed by local electrochemical impedance.

\subsection{Detection and quantification of the underpaint defects in conversion coating by LEIM}

Global EIS measurement presented in Fig. 7 suggests that for frequencies below $1 \mathrm{kHz}$, in the region where the second time constant can be seen, one should be sensitive to the electron charge transfer at the metal/oxide/polymer interface. Therefore, LEIM experiments were performed at $400 \mathrm{~Hz}$ that is a tradeoff value to localize the defects under the paint and to speed up the time of map acquisition. Additionally, some preliminary experiments at lower frequencies did not allow the detection of smaller defects.

<Fig.9>

Fig. 9 presents the examples of the local impedance modulus distribution mapped in the vicinity of the defects on the samples $A, B$ and $C$ produced from the same batch during the first 
(Fig. 9a) and the fourth (Fig. 9b) degradation cycles. The lower the impedance modulus, the darker the color of the area. During the first degradation cycle, all the samples A, B and C from different batches showed the presence of a lower impedance area at the location of the nanometric defects in the conversion coatings. The defect of type $D$ was not detectable, and the results are not present. The comparison of the maps obtained after the $1^{\text {st }}$ and the $4^{\text {th }}$ cycle shows that the impedance modulus decreases on the whole scanned surface and the reactivity of the initially intact surface becomes more heterogeneous. This behavior is characteristic for all the batches and is observable during the whole cycle procedure. Interestingly, after the $4^{\text {th }}$ cycle only the millimeter size defects of the samples $A$ and $B$ could be detected by LEIM, while the defects grid $C$ is hindered by the increased reactivity of the initially intact interface.

Fig. 10 presents the maps of the local gradient of the impedance calculated from the results presented in Fig. 9. In our previous work [48], we showed that extremes in Fig. 10 indicate the border of the electrochemically active regions. The values of the gradient are normalized by the maximum gradient value of each map to evidence the position of the delamination front by the same color code in all images. The specific shape of the maximum of the gradient for samples $A$ and $B$ is attributed to the borders delimiting zones with different electrochemical activity. Similarly, to the impedance maps (Fig. 9), the defect can be seen on the samples A, B and C after the first cycle, and only for the samples A and B after four cycles.

\section{$<$ Fig.10>}

To extract the defect size, the defects shape was approximated by a circle. The black circle in dashed line (Fig. 10) illustrates the chosen positions of the local extremum of the gradient. The diameters of the circles in Fig. 10 correspond to the maximal distance between the extremes of the gradient of admittance maps in Fig. 9 (calculated with the software described in [48]). As previously noted, the position of the extremes of the gradient of admittance indicates the interface between the less active delaminated and more active intact buried interface. So, in the approximation of the circular defect, the circle diameter corresponds to the linear size of the electrochemically active zone.

Only for the samples type $A$ and $B\left(D_{0}=3.8\right.$ and $\left.1.8 \mathrm{~mm}\right)$, the defect was well defined through the ageing procedure (see Fig. 10). For these samples, the evolution of the average linear size of the defect was estimated from the gradient maps at different steps of AC-DC-AC cycling and the confidence intervals were obtained for the samples from 3 different batches. Fig.11 represents the evolution of the average linear size of the underpaint defects and the confidence interval as a function of the degradation cycle number for the samples of types $A$ and $B\left(D_{0}=3.8\right.$ and 1.8 $\mathrm{mm}$ ). First, the detected size by the electric signal of the initially active zone for both samples is different from the size measured by optical microscopy before the degradation procedure. Sample $A$ has an average active zone of $3.5 \mathrm{~mm}$ in diameter instead of the expected $3.8 \mathrm{~mm}$ whereas sample B shows a $2 \mathrm{~mm}$ in diameter active zone instead of the expected $1.8 \mathrm{~mm}$. As 
1 Hence the possible difference between the size of detected reactivity and the size of the actual

2 conversion coating thinning can be ascribed to the distribution of cathodic and anodic areas at 3 the defect.

Additionally, the evolution of the size of the active zone evolves in several steps according to:

1) Initiation: the size of the defect varies

- Increases on sample A with $3.8 \mathrm{~mm}$ defect up to cycle 1

- Decreases on sample $B$ with smaller defect up to cycle 3

2) Stabilization: the detected size of the defect is stable.

- From cycle 2 to 4 on sample $A$ with a $3.8 \mathrm{~mm}$ defect

- From cycle 3 to 7 on sample $B$ with a $1.8 \mathrm{~mm}$ defect

3) In the case of the biggest defect (sample A) after the stability phase, the size of the detected defect slightly increases, which can be attributed to the degradation of the metal-polymer interface in the front positions of the initial defect and gradual delamination of the polymer coating from the active defect. This stage was not achieved in the case of the smaller defect (sample B), suggesting a re-passivation of the defect front.

\section{<Fig.11>}

\subsection{Ex situ optical observations in the vicinity of the defect after cycling}

Fig. 12a presents typical optical micrographs in grazing light, recorded around the defects after the complete degradation procedure for the samples of type $A\left(D_{0}=3.8 \mathrm{~mm}\right.$, gradual reactivity increases and defect size increases, as detected by LEIM) and $\mathrm{B}\left(D_{0}=1.8 \mathrm{~mm}\right.$, reactivity stabilization and defect size stabilization detected by LEIM). The dashed red line represents an estimated position of the defect borders. The area inside the defect A looks different from the outside of the defect: the lighter spots are present which are attributed to blisters reflecting the grazing light. Conversely, the smaller defect is difficult to detect (sample B) since the surface of the defect appears lighter than the rest of the sample but no signs of evident degradation of the system can be noticed.

\section{<Fig.12>}

Fig. 12b shows high magnification 3D composition images performed near the center of the defect on the samples A, B and on the intact sample I. Images revealing the top polymer surface (on the left) and the substrate under the paint (on the right) are shown. The analysis of the paint surface in the defect of sample A (Fig. 12b, on top-left)) shows that the polymer is deformed and rough: the grazing light comes from the right side of the image, thus the inhomogeneity of the paint surface is visible thanks to the light reflection.

Topographical analysis of the top surface inside the defect, was made by the measurements of the height of each focused pixel. This analysis revealed a height increase of approximately 15 $\mu \mathrm{m}$ in the zone with strong light reflection in comparison to the white zones. The height increase 
of $15 \mu \mathrm{m}$ is 1.5 times bigger than the polymer thickness and 3 times higher than the $R_{a}$ value of the substrate $(5 \mu \mathrm{m})$. This boosted height of the top surface can be related either to the increase of the polymer thickness (swelling) or to the detachment of the polymer from the substrate and increase of the distance between the substrate and the polymer (blistering). Because of the shape and localization of this protrusion, it is attributed to blistering.

For comparison, 3D composition images of the samples of type B and I (Fig. 12b, on the left, middle and bottom pictures, respectively) did not reveal the formation of blisters. On these images, the focus on the paint surface was ensured by the micro scratch performed on the surface preliminary to the observation and visible by little dark dots. Only the underpaint substrate shows light reflection, but the paint surface looks flat and smooth.

The images with focus on the underpaint substrate (Fig. 12b, right pictures) demonstrate another difference between the degradation mode of the sample of type A (active increasing defect, upper image) and the two others. For the intact sample I and the sample with the defect of type $B$, the substrate reflects the typical morphology and the color of the initial $\mathrm{Zn}$ alloy with conversion coating and shows no sign of degradation. For the sample A, specifically in the location of the blister detailed above, the substrate surface changes the color demonstrating the appearance of metallic light gray (close to white) areas. Such a color is typical for the Zn-alloy substrate not treated with conversion coating. It was indeed observed on the substrate prior to the conversion coating procedure. The presence of close to white zones reflects therefore a local lack of conversion coating. Interestingly, no traces of corrosion products are visible in the blisters at least at the time-scale of the experiments.

\section{Discussion: LEIM detection of nanometer in-depth defects in conversion coating with micrometric roughness}

Although metal-polymer systems have been extensively studied by multiple groups, to our knowledge, all the reported local observations of the system degradation were initiated by damaging the polymer coating or by adding reactivity enhancing agents at the metal-polymer interface. Even though several works studied the stability of the oxide-polymer interfaces (see the recent review [55]), to our knowledge no systematic study was focused on the effects of the local thinning of the conversion oxide layer (without its complete degradation) on the local stability of the system. The defects in conversion coating were previously studied $[19,47,56]$ mainly in relation to the coating performance and average evolution of the system but without considering the local evolution of the defects surrounded by a non-defect matrix. In this work, controlled local nanometric thinning of the conversion coating was performed prior to the model epoxy paint application. One of the main objectives of the work was to explore the analytical capacity of different methods (global impedance, LEIM, cathodic charge, optical inspection) to 
detect and to describe the evolution of these buried nanometer thick defects in conversion coatings formed on the substrates with micrometric roughness.

First, we evaluated the minimum defect area which can be detected on the four types of spatial distribution of the thinned zones in conversion coatings, which were produced in a controlled way prior to painting. For these defects, the area fraction occupied by the defect on the total reacting surface in the electrochemical cell represents between 3.30 and $0.01 \%$. Thus, two main reasons could lead to analytical limitations in their detection: the instrumental limitations of the used setup and the low contribution of the defect to the electrochemical response compared to the noise related to the initial inhomogeneity of the interface because of its micrometric roughness.

The possibility or not to detect four studied types of the defect are summarized in Table 3.

\section{$<$ Table 3>}

For the grid of defects with the total damaged zone smaller than $0.09 \mathrm{~mm}^{2}$ (sample D), the presence of this initial defect zone was not evidenced by any of the tested techniques. The electrochemical response and the degradation mode of the samples with such a defect were similar to what has been observed for the intact samples (sample I). Considering the macroscopic detection techniques (EIS, polarization current, OCP etc.), the impossibility to see the effect could be explained by a small defect area representing less than $0.1 \%$ of the analyzed surface. However, the defect size $D_{0}$ is in the same order of magnitude than the scanned area by the local electrochemical impedance probe $(0.3 \times 0.3 \mathrm{~mm})$; hence the technique should be able to detect the influence in the normal contribution of the current during impedance measurement. One should however note, that a shadowing effect during the ToF SIMS sputtering, discussed in [44], can result in the fact that the real thinned area is even smaller, which could explain the impossibility of the detection of so small defect. From the other side, it is reasonable to suppose that the inhomogeneity introduced by a so small defect is comparable with the initial inhomogeneity of the system related to the micrometric substrate roughness, which could result in initial inhomogeneity of the conversion coating and the polymer thickness.

One could also expect that the tip size and the tip to substrate distance can limit the detection of the defects less than $70 \mu \mathrm{m}$. The grid of 49 defects with linear size of $70 \mu \mathrm{m}$, leading to a damaged zone of about $0.49 \mathrm{~mm}^{2}$ area, was however detected before ageing. At the same time, the local reactivity in the defect was not distinguishable once the initially intact surface started to degrade, so after 4 or more cathodic polarization cycles. This can be interpreted as either the influence of the defect becomes negligible compared to the average ageing of the metal-oxidepolymer interface in the initially intact zones, or that the defect can heal with cathodic polarization cycling. It is likely that a thinning of the conversion coating to less than $10 \mathrm{~nm}$ on only 9 or 49 spots of $0.0049 \mathrm{~mm}^{2}$ area each does not significantly influence the stability of the painted system on the substrate with initial micrometric roughness. 
All the defect zones with the area more than $0.6 \mathrm{~mm}^{2}$ ( $\mathrm{A}, \mathrm{B}$ and $\mathrm{C}$ ) were detected by all the techniques. Hence, a local thinning of the conversion coating on the areas with $\mathrm{mm}^{2}$ size or more seems to significantly affect the underpaint reactivity and could be detected by electrochemical methods.

In addition, the treatment of LEIM data allowed to measure in situ the size evolution of the active zone induced by the nanometric thinning of the conversion coating during the ageing procedure and distinguish two different degradation behaviors (local defect expansion and local interface stabilization) which were confirmed by ex situ optical observation.

The coherence between LEIM measurements and optical observations validates the ability of LEIM to evaluate the kinetics of interface degradation in immersion conditions for initially undamaged coated systems. Although LEIM had already been used to track quantitatively the polymer delamination on weakly adherent coatings and model systems with highly resistive coatings, all the reported quantitative works measured the delamination from an artificially produced defect in the paint (see for instance $[28,36]$ ).

\section{Conclusions}

For the first time the effect of the nanometer depth thinning in conversion coating on the stability of buried metal-oxide-polymer interface formed on the substrate with micrometric roughness was studied. It was demonstrated that electrochemistry is able to detect the initially present thinning in conversion coating, including the small defects with diameter smaller than 1 $\mathrm{mm}$, which are not optically detectable after the paint application.

The local thinning of the trivalent chromium conversion coating on $\mathrm{Zn}$ alloy leads to a localized initial increase of the activity at buried metal-oxide-polymer interface in the vicinity of the defect.

The local thinning of conversion coating on the rough substrate do not mandatory lead to enhanced underpaint degradation after painting. In some cases, the surface inhomogeneity related to the initial roughness hinders the effect of the artificial thinning.

LEIM was able to measure in situ the degradation kinetics and distinguish the defects, for which the interface suffered severe degradation, from the defects, which reached a certain stability in both terms of the defect size and underpaint reactivity. The measured ranking of degradation rates by LEIM was confirmed by ex situ high resolution optical observations and 3D images reconstruction thus validating quantitative LEIM as a tool for the local degradation quantification for buried interfaces.

\section{Acknowledgements}

The authors are grateful for Dr. Antoine Seyeux for the production of $\mu \mathrm{m}$ size defects by ToF SIMS and Dr. Sandrine Zanna for the XPS measurement of the composition inside the mm size defect. 
[1] Total Materia, Corrosion protection of Steel [Online], available on: https://www.totalmateria.com/page.aspx?ID=CheckArticle\&site=kts\&NM=300, [Accessed on 16/08/2020]

[2] N. K. Akafuah, S. Poozesh, A. Salaimeh, G. Patrick, K. Lawler, K. Saito, Evolution of the Automotive Body Coating Process-A Review, Coatings, 24 (2016) 1-22

[3] W. Funke. Corrosion Control by Coatings, H. Leidheiser, Jr., Editor, Science Press, Princeton, N. J., p. 35 (1979)

[4] M. Schneider, U. Gierth, L. Simunkova, P. Gierth, L. Rebenklau, Complementary EIS/FTIR study of the degradation of adhesives in electronic packaging, Materials and Corrosion (2020), DOI: $10.1002 /$ maco. 202011772

[5] M.A. Sebaa, S. Dhillon, H. Liu, Electrochemical deposition and evaluation of electrically conductive polymer coating on biodegradable magnesium implants for neural applications, Journal of Material Science: Materials in Medecine 24 (2013), 307-316

[6] D.M. Johnson, Zinc and cadmium passivation bath, US2559878A, (1951)

[7] W. Zhou, D. Shan, E.-H. Han, W. Ke, Structure and formation mechanism of phosphate conversion coating on die-cast AZ91D magnesium alloy, Corros. Sci., 50 (2008) 329-337

[8] O. Lunder, C. Simensen, Y. Yu, K. Nisancioglu, Formation and characterization of Ti-Zr based conversion layers on AA6060 aluminium, Surf. Coat. Technol., 184 (2004), 278-290

[9] W. Funke, Toward a unified view of the mechanism responsible for paint defects by metallic corrosion, Ind. Chem. Prod. Res. Dev. 24 (1985), 343-347

[10] W. Funke, Problems and progress in organic coatings science and technology, Progress in Organic Coatings 31 (1997), 5-9

[11] G. Grundmeier W. Schmidt M. Stratmann Corrosion protection by organic coatings: electrochemical mechanism and novel methods of investigation, Electrochimica Acta 45 (2000) 2515-2533

[12] VDA 233-102:2013, Cyclic corrosion testing of materials and components in automotive construction, Verband der Automobilindustrie (VDA), Berlin, Germany, June 2013

[13] J.W. Hwang, M.J. Yim, K.W. Paik, Effects of thermoplastic resin content of anisotropic conductive films on the pressure cooker test reliability of anisotropic conductive film flip-chip assembly, Journal of Electronic Materials 34 (2005), 1455-1461

[14] ASTM International D 870 - 15 "Standard practices for testing water resistance of coatings using water immersion" (2020)

[15] ASTM International D $714-02$ "Standard test method for evaluating degree of blistering of paints" (2017)

[16] B. Munirathinam, J.P.B. van Dam, A. Herrmann, W.D. Driel, F. De Buyl, S.J.F. Erich, L.G.J. van der Ven, O.C.G. Adan, J.M.C. Mol, Exploring water and ion transport process at silicone/copper interfaces using in situ electrochemical and Kelvin probe approaches, Journal of Materials Science \& Technology (2019), https://doi.org/10.1016/j.jmst.2019.07.044

[17] M. Stratmann, Whitney Award Lecture: Corrosion Stability of Polymer-Coated MetalsNew Concepts Based on Fundamental Understanding, CORROSION 2005, Vol. 61, No. 12, pp. $1115-1126$ 
[18] M. Stratmann, G. Grundmeyer, Adhesion and de-adhesion mechanisms at polymer/metal interfaces: mechanistic understanding based on in situ studies of buried interfaces, Annual Rev. Mater. Res. 35 (2005), 571-615

[19 ]A. Gonzalez-Orive, I. Giner, T. de los Arcos, A. Keller, G. Grundmeyer, Analysis of polymer/oxide interfaces under ambient conditions - An experimental perspective, Applied Surface Science 442 (2018), 581-594

[20] M. Poelman, M-G. Olivier, N. Gayarre, J-P. Petitjean, Electrochemical study of different ageing tests for the evaluation of a cataphoretic epoxy primer on aluminium, Progress in Organic Coatings 54 (2005), 55-62

[21] P. Taheri, H. Terryn, J.M.C. de Mol, Studying interfacial bonding at buried polymer-zinc interfaces, Progress in Organic Coatings 89 (2015), 323-331

[22] F. Meng, L. Liu, Electrochemical evaluation technologies of organic coatings, Intechopen (2018) [Online] available on https://www.intechopen.com/books/coatings-and-thin-filmtechnologies/electrochemical-evaluation-technologies-of-organic-coatings, [Accessed on 10/02/2019]

[23] A. Amirudin, D. Thierry, Application of electrochemical impedance spectroscopy to study the degradation of polymer-coated metals, Progress in Organic Coatings 26 (1995), 1-28

[24] E.P.M. van Westing, G.M. Ferrari, J.H.W de Wit, The determination of coating performance with impedance measurement-I. Coating polymer properties, Corrosion Science 34 (1993), 1511-1530

[25] E.P.M. van Westing, G.M. Ferrari, J.H.W de Wit, The determination of coating performance with impedance measurement-III. in situ determination of loss of adhesion, Corrosion Science 36 (1994), 979-994

[26] E.P.M. van Westing, G.M. Ferrari, J.H.W de Wit, The determination of coating performance with impedance measurement-II. in situ determination of loss of adhesion, Corrosion Science 36 (1994), 957-977

[27] S. Amand, M. Musiani, M.E. Orazem, N. Pebere, B. Tribollet, V. Vivier, Constant-phaseelement behavior caused by inhomogeneous water uptake in anti-corrosion coatings, Electrochimica Acta 87 (2013), 693-700

[28] G. Grundmeier, W. Schmidt, M. Stratmann, Corrosion protection by organic coatings: electrochemical mechanism and novel methods of investigation, Electrochimica Acta 45 (2000), 2515-2533

[29] A. Nazarov, T. Prosek, D. Thierry, Application of EIS and SKP methods for the study of the zinc/polymer interface, Electrochimica Acta 53 (2008), 7531-7538

[30] G. Williams, A. Gabriel, A. Cook, H.N. McMurray, Dopant effects in Polyaniline inhibition of corrosion-driven organic coating cathodic delamination on iron, Journal of the Electrochemical Society 153 (2006), 425-433

[31] H.S. Isaacs, Initiation of stress corrosion cracking of sensitized type 304 stainless steel in dilute thiosulfate solution, Journal of the Electrochemical Society 135 (1988), 2180

[32] A.C. Bastos, M.C. Quevedo, O.V. Karavai, M.G.S. Ferreira, Review - On the application of Scanning Vibrating Electrode Technique (SVET) to corrosion research, Journal of the Electrochemical Society 164 (2017), 14

[33] F. Zou, D. Thierry, H.S. Isaacs, J. Electrochem. Soc. 144 (1997) 1957-1965 
[34] V.M. Huang, S.L. Wu, M.E. Orazem, N. Pebere, B. Tribollet, V. Vivier, Local electrochemical impedance spectroscopy: a review and some recent developments, Electrochimica Acta 56 (2011), 8048-8057

[35] J-B. Jorcin, E. Aragon, N. Pébère, Delaminated areas beneath organic coating: A local electrochemical impedance approach, Corrosion Science 48 (2006) 1779-1790

[36] V. Shkirskiy, P. Volovitch, V. Vivier, Development of quantitative Local Electrochemical Impedance Mapping: an efficient tool for the evaluation of delamination kinetics, Electrochimica Acta 235 (2017) 442-452

[37] L.V.S. Philippe, G.W. Walter, S.B. Lyon, Investigating localized degradation of organic coatings: comparison of electrochemical impedance spectroscopy with local electrochemical impedance spectroscopy, Journal of the Electrochemical Society 150 (2003), B111-B119

[38] Z. Kefallinou, S.B. Lyon, S. Gibbon, A bulk and localized electrochemical assessment of epoxy-phenolic coating degradation, Progress in Organic Coatings 102 (2016), 88-98

[39] G. Williams, and H.N. McMurray, The mechanism of group (I) chloride initiated filiform corrosion on iron, Electrochemical Communications 5 (2003), 871-877

[40] V. Shkirskiy, A. Krasnova, T. Sanchez, A. Amar, V. Vivier, P. Volovitch, Development of anodic and cathodic blisters at a model Zn/epoxy interface studied using local electrochemical impedance, Electrochemistry Communications 111 (2020), 106633

[41] T. Sanchez, S. Gillet, V. Shkirskiy, V. Vivier, J. Echouard, J. Swiatowska, P. Volovitch, A new system for intelligent screening of buried interfaces: local electrochemistry characterization of undamaged model epoxy coated Zn alloys, Electrochim. Acta 367C (2021), 137411

[42] U.S. EPA (1998) Principles of Environmental Impact Assessment Review: Appendix A: Environmental Impact Assessment Checklist

[43] European Commission regulation report $n^{\circ} 2017 / 999$ - REACH, Official Journal of European Union (2017)

[44] T. Sanchez, S. Zanna, A. Seyeux, M. Vaudescal, P. Volovitch, J. Swiatowska, Conversion coating distribution on rough surfaces analyzed by combining surface analytical techniques, Appl. Surf. Sci. (2021) 149734, https://doi.org/10.1016/j.apsusc.2021.149734.

[45] G.D. Wilcox, Electrodeposited zinc alloy coatings, Corrosion Science 35 (1993), 1251-1258

[46] G. Wilcox, Replacing chromates for the passivation of zinc surfaces, Transactions of the Institute of Metal Finishing 81 (2003), B13-B15

[47] X. Zhang, C. van den Bos, W.G. Sloof, A. Hovestad, H. Terryn, J.H.W. de Wit, Comparison of the morphology and corrosion performance of $\mathrm{Cr}(\mathrm{VI})$ - and $\mathrm{Cr}(\mathrm{III})$-based conversion coatings on zinc, Surface and Coating Technologies 1999 (2005), 92-104

[48] V. Shkirskiy, P. Volovitch, V. Vivier, Development of quantitative Local Electrochemical Impedance Mapping: an efficient tool for the evaluation of delamination kinetics, Electrochimica Acta 235 (2017) 442-452

[49] Keyence Corporation, Keyence VHX Digital Microscope, Quality 53 (2014), S47

[50] Keyence Corporation (Osaka, JP), Three-dimensional image processing apparatus, threedimensional image processing method, three-dimensional image processing program, computerreadable recording medium, and recording device, US Patent 9,756,314, issued September 5, 2017

[51] D. Necas, P. Klapetek, Gwyddion: an open-source software for SPM data analysis, Central European Journal of Physics 10 (2012), 181-188 
[52] J.R. Scully, S.T. Hensley, Lifetime prediction for organic coatings on steel and a magnesium alloy using electrochemical impedance methods, Corrosion 50 (1994) 705-716

[53] A. Nguyen, N. Causse, M. Musiani, M. Orazem, N. Pébère, B. Tribollet, V. Vivier, Determination of water uptake in organic coatings deposited on 2024 aluminium alloy: Comparison between impedance measurements and gravimetry, Progress in Organic Coatings 112 (2017) 93-100

[54] M. Benoit, C. Bataillon, B. Gwinner, F. Miserque, M.E. Orazem, C. M. Sánchez-Sánchez, B. Tribollet, V. Vivier, Comparison of different methods for measuring the passive film thickness on metals, Electrochimica Acta 201 (2016) 340-347

[55] S. Pletincx, L. Lynn, I. Fockaert, J.M.C. Mol, T. Hauffman, H. Terryn, Probing the formation and degradation of chemical interactions from model molecule/metal oxide to buried polymer/metal oxide interfaces, NPJ Materials Degradation 3 (2019), 23

[56] D.H. Van der Weijde, E.P.M. Van Westing, J.D.H. de Wit, Electrochemical techniques for delamination studies, Corrosion Science 36 (1994), 643-652 

Tables.

Table 1. Chemical composition of the coating detected by XPS in the intact sample and inside an artificial crater (defect) of $4 \mathrm{~mm}$ diameter

\begin{tabular}{|c|c|c|}
\hline Element & $\begin{array}{c}\text { at. \% in intact coating } \\
\text { (3 measurements) }\end{array}$ & at. \% inside the defect \\
\hline $\mathrm{Zn}$ & $13 \pm 1$ & $13 \pm 1$ \\
\hline $\mathrm{O}$ & $79 \pm 1$ & $80 \pm 1$ \\
\hline $\mathrm{Ni}$ & Not detected & Not detected \\
\hline $\mathrm{Cr}$ & $8 \pm 1$ & $7 \pm 1$ \\
\hline
\end{tabular}

Table 2. Different types of defects, produced in conversion coating prior to epoxy polymer application. Parameters used in the Table are defined in the text and in Fig. 1

\begin{tabular}{|c|c|c|c|c|c|c|}
\hline \multirow{2}{*}{ Sample } & \multirow{2}{*}{$\begin{array}{c}\text { Erosion } \\
\text { technique }\end{array}$} & \multicolumn{2}{|c|}{$\begin{array}{c}\text { Individual crater diameter } \\
\boldsymbol{d} / \boldsymbol{\mu m}\end{array}$} & \multicolumn{2}{c|}{ Craters arrangement in defect zone } & $\begin{array}{c}\text { Considered } \\
\text { defect } \\
\text { dimension } \\
\mathrm{D}_{0} / \mathrm{mm}\end{array}$ \\
\cline { 3 - 6 } & Targeted & Measured & $\begin{array}{c}\text { Grid size } \\
\mathrm{N} \times \mathrm{N}\end{array}$ & Inter-crater distance $/ \mu \mathrm{m}$ & - \\
\hline I & No craters & - & - & - & - & 3.8 \\
\hline $\mathrm{A}$ & GD-OES & 4000 & $3800 \pm 20$ & - & - & 1.8 \\
\hline B & GD-OES & 2000 & $1800 \pm 20$ & - & - & 0.8 \\
\hline C & ToF-SIMS & 30 & $70 \pm 5$ & $7 \times 7=49$ & 0.04 & 0.3 \\
\hline D & ToF-SIMS & 30 & $70 \pm 5$ & $3 \times 3=9$ & 0.04 & -3 \\
\hline
\end{tabular}

Table 3. Capacity of different techniques to detect and describe local thinning in conversion layer under $10 \mu \mathrm{m}$ thick epoxy coating for the model systems with different lateral size of the thinned zone.

\begin{tabular}{c|c|c|c|c|c|c}
$\begin{array}{c}\mathbf{D}_{0} \\
\text { /mm }\end{array}$ & Defect type & $\begin{array}{c}\text { Detection } \\
\text { cathodic } \\
\text { charge }\end{array}$ & $\begin{array}{c}\text { Detection } \\
\text { TLM }\end{array}$ & $\begin{array}{c}\text { Detection } \\
\text { LEIM }\end{array}$ & $\begin{array}{c}\text { Size } \\
\text { quantification } \\
\text { LEIM }\end{array}$ & $\begin{array}{c}\text { Size } \\
\text { evolution } \\
\text { LEIM }\end{array}$ \\
\hline 3.8 & A, single crater & $\checkmark$ & $\checkmark$ & $\checkmark$ & $\checkmark$ & $\checkmark$ \\
\hline 1.8 & B, single crater & $\checkmark$ & $\checkmark$ & $\checkmark$ & $\checkmark$ & $\checkmark$ \\
\hline 0.8 & C, grid of craters & $\sim$ & $X$ & $\checkmark$ & $\checkmark$ & $X$ \\
\hline 0.3 & D, grid of craters & $X$ & $X$ & $X$ & $X$ & $X$
\end{tabular}


Figures captions.

2 Fig. 1. (a) Cross sectional and (b-c) top view schematics of model systems for the parameters definition. Linear dimension $d$ and depth $0.8 h$, where $h$ is the initial conversion coating thickness) of an individual defect as well as the grid size $\mathrm{N} \times \mathrm{N}$ and the considered initial linear defect size (D) are shown

Fig. 2. Examples of 3D-microscopy images and corresponding topographic profiles of surfaces with defect in conversion coating produced by (a) GD-OES ( $2 \mathrm{~mm}$ crater, sample B) and (b) ToFSIMS (grid of 49 craters, sample $\mathrm{C}$ ). The imaging is made before polymer coating.

Fig. 3. Schematic representation of an ageing electrochemical cycle.

Fig. 4. Time Lapse Microscopy images of samples $A, B$ and $C\left(D_{0}=3.8,1.8\right.$ and $0.8 \mathrm{~mm}$, respectively) at the beginning of first and fourth degradation cycles.

Fig. 5. Examples of (a) OCP evolution during the relaxation stage and (b) potentiostatic current evolution during cathodic polarization for different cycles as indicated.

Fig. 6. Total charge, passed during cathodic polarization stage of the degradation cycle, as a function of the cycle number, for the samples with different initial dimension of the defect zone Figure (c) plots cathodic charge as a function of the area of the damaged zone for the first, the fourth and the seventh degradation cycles.

Fig. 7. Examples of Bode plots (modulus (a) and phase angles (b)) of different samples, recorded at different ageing cycles, as indicated.

Fig. 8. Evolution of capacitance $C$, calculated by eq. 1 , as a function of the ageing cycle number for different samples. The samples from the same batch are indicated by the same symbol. Open symbols are used for the samples with defect $\left(D_{0}=3.8 \mathrm{~mm}\right)$, circles - for the samples without defect.

Fig. 9. LEIM maps of the local impedance modulus, $|Z|$ in the vicinity of the defects for samples $A, B$ and $C\left(D_{0}=3.8,1.8\right.$ and $0.8 \mathrm{~mm}$, respectively) at first and fourth degradation cycles Fig. 10. Maps of the gradient of the local impedance modulus, Grad $|Z|$ in the vicinity of the defects for samples $A, B$ and $C$ ( $D_{0}=3.8,1.8$ and $0.8 \mathrm{~mm}$, respectively) at the first and fourth degradation cycles. All the values are normalized by the value of the maximum of gradient through the map.

Fig. 11. Evolution of the LEIM measured size of the defects with degradation cycling for samples $A\left(D_{0}=3.8\right.$, black squares) and $B\left(D_{0}=1.8 \mathrm{~mm}\right.$, red dots).

Fig. 12. Optical micrographs showing (a) the general appearance of the defect for samples $A$ (left) and $B$ (right) after ageing procedure (7 cycles) and (b) high resolution images in the center of the defect for the samples A, B and I with the focus on the top of the polymer coating (left) and at metal-polymer interface (right). 


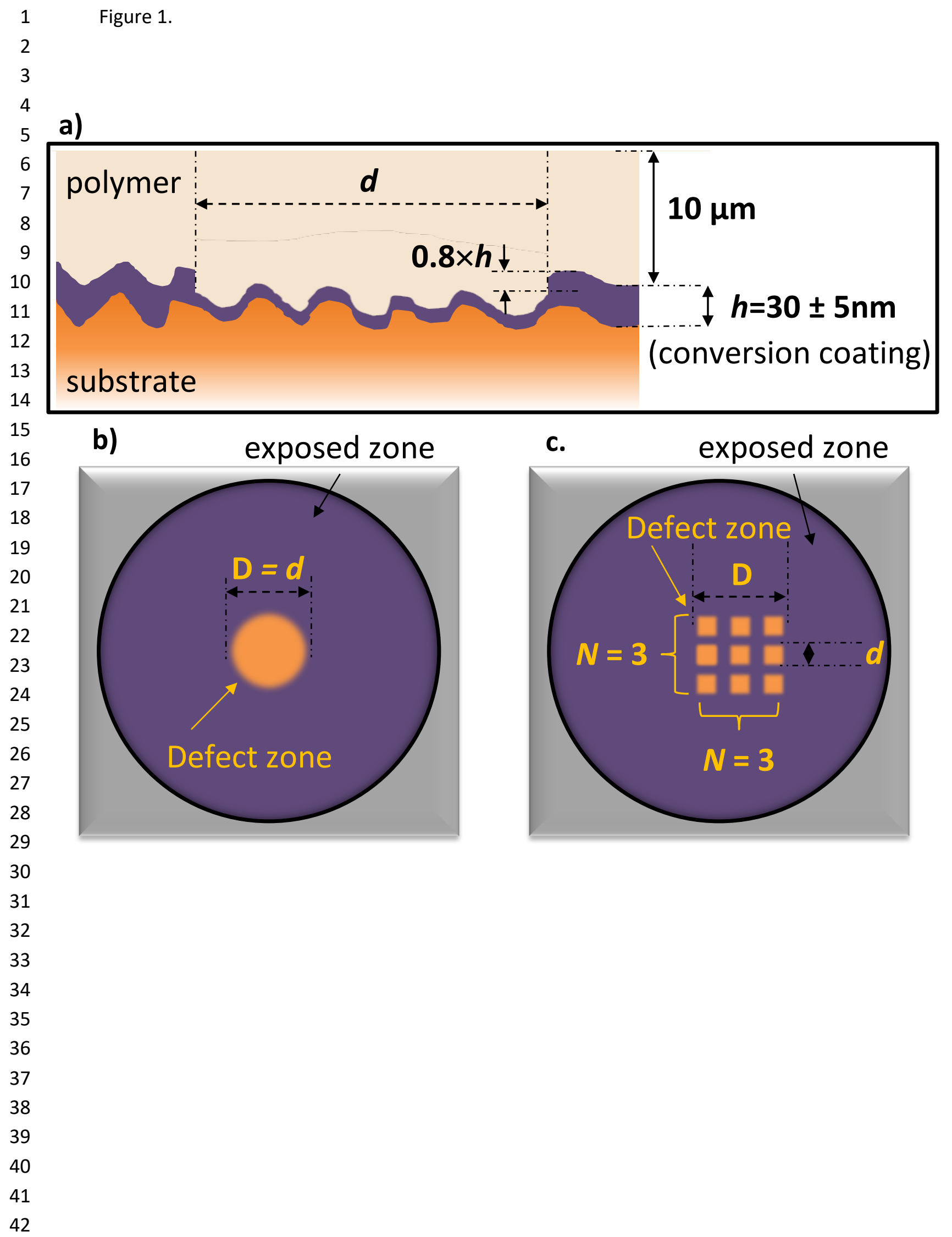




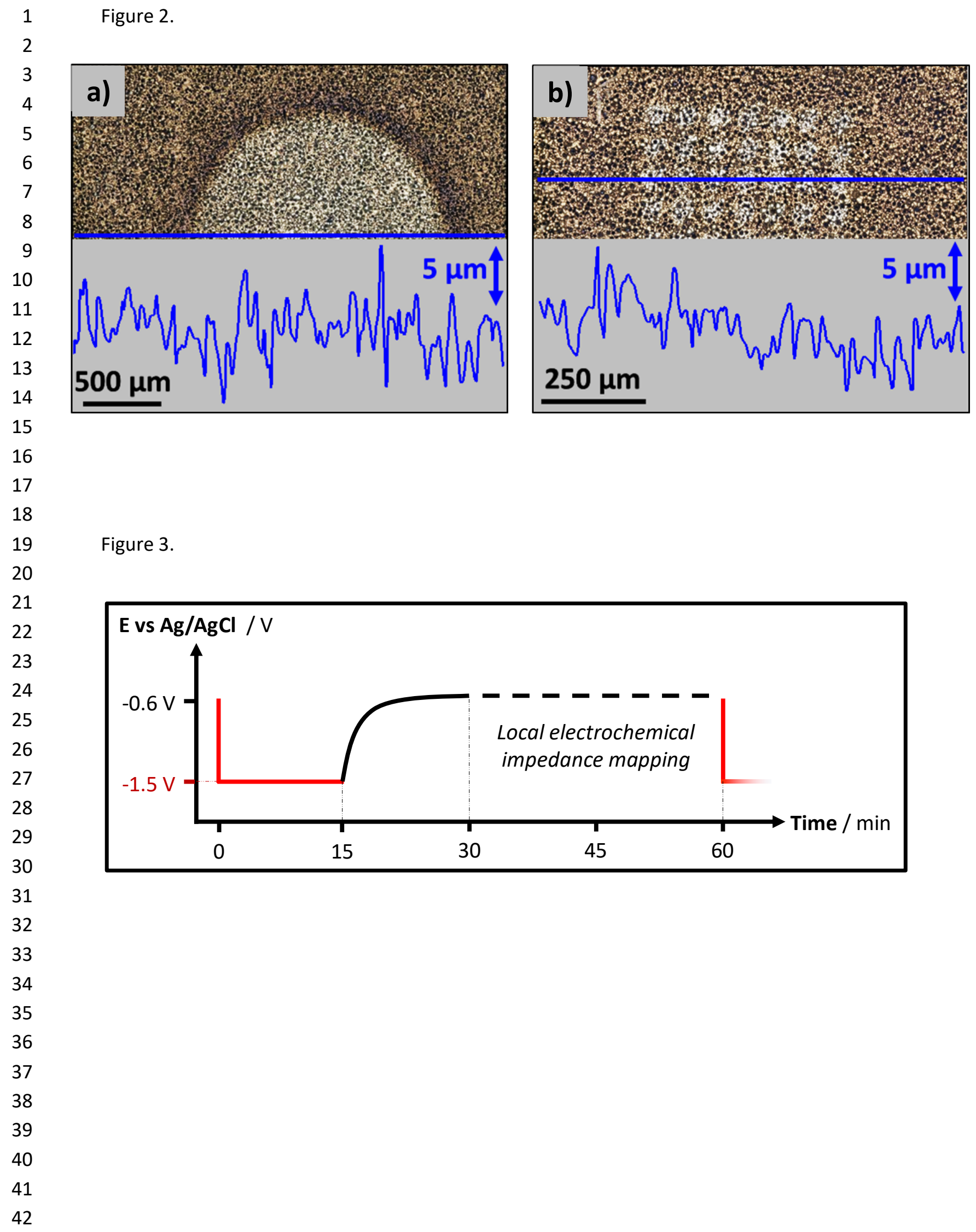


$1 \quad$ Figure 4.

2

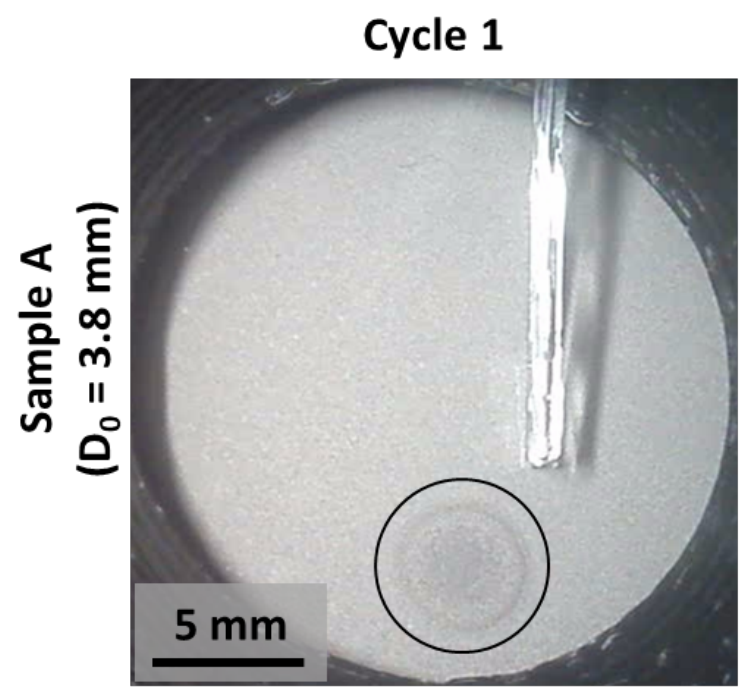

Cycle 4
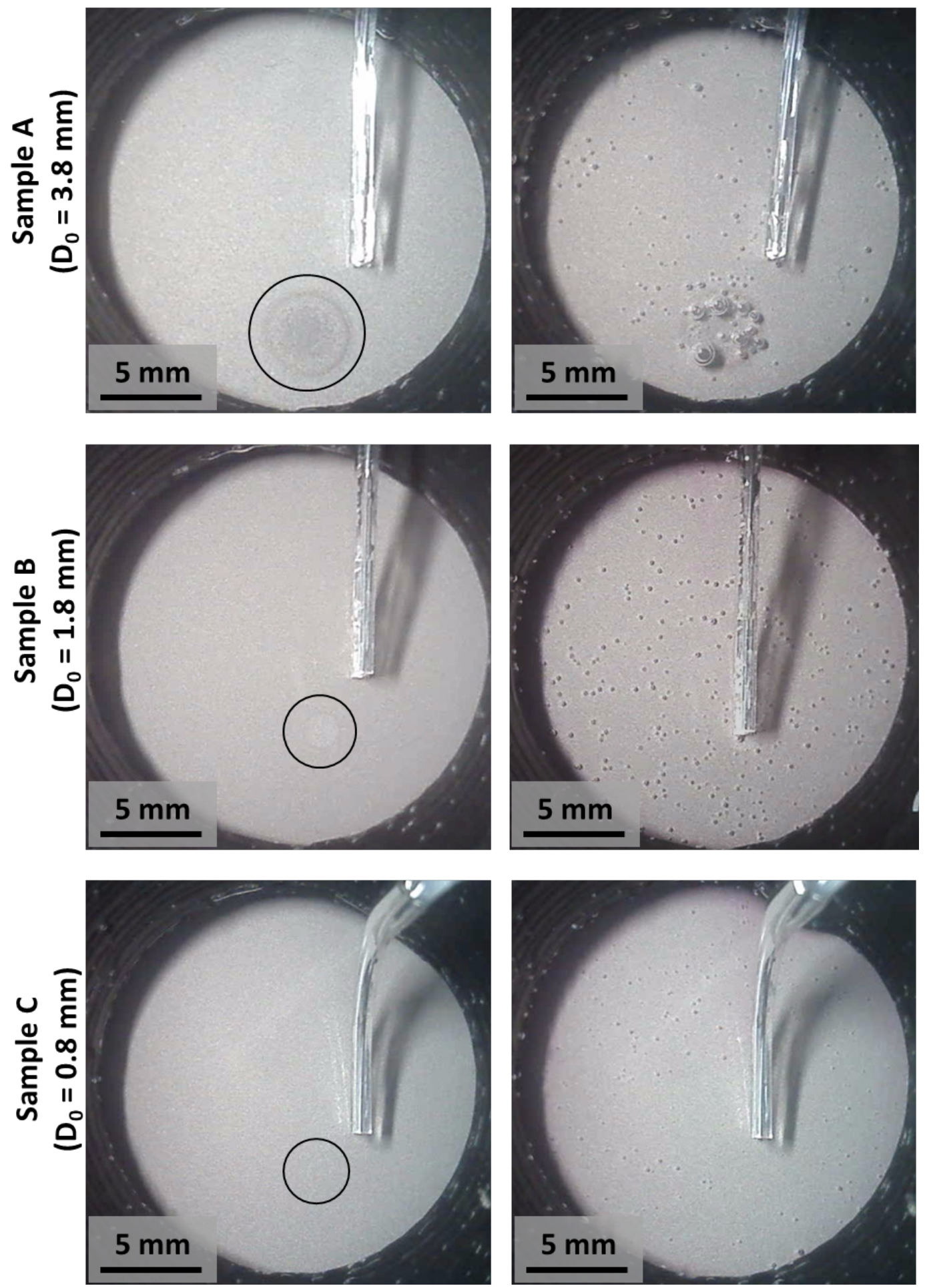
Figure 5.

2

a)
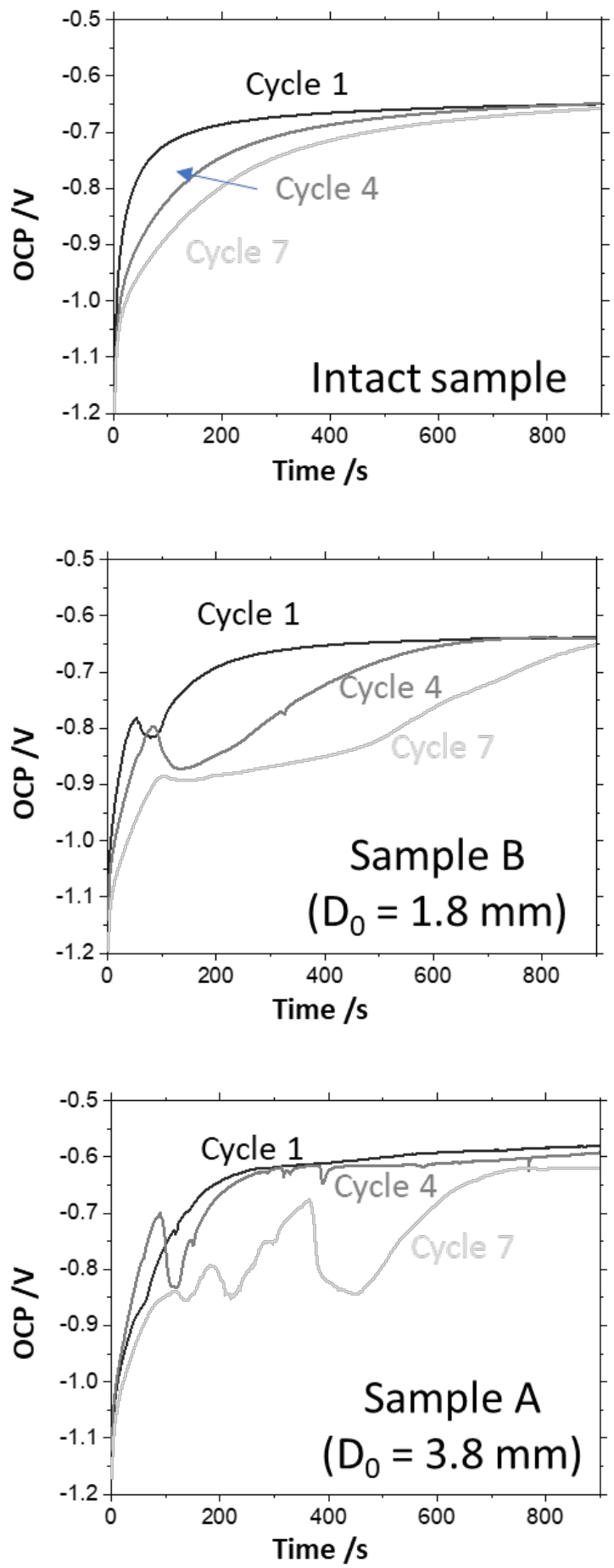

b)
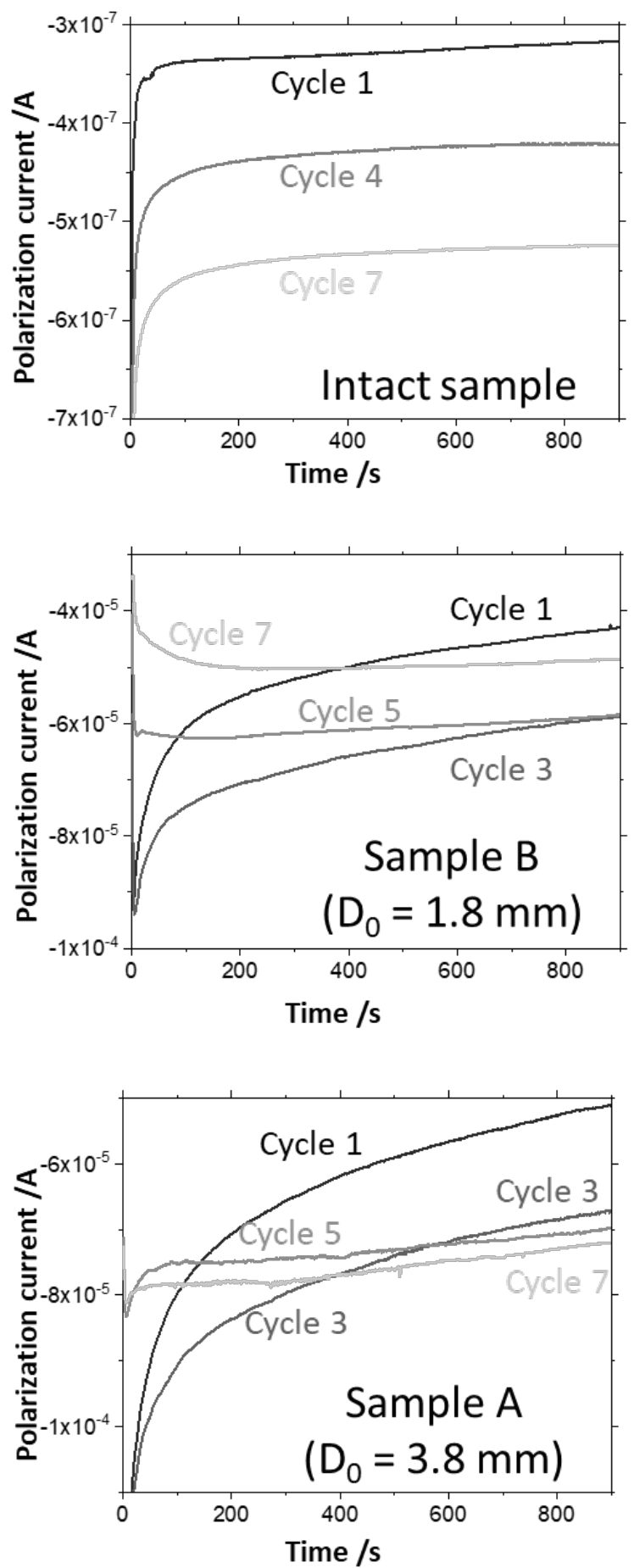
1

2

3

a)

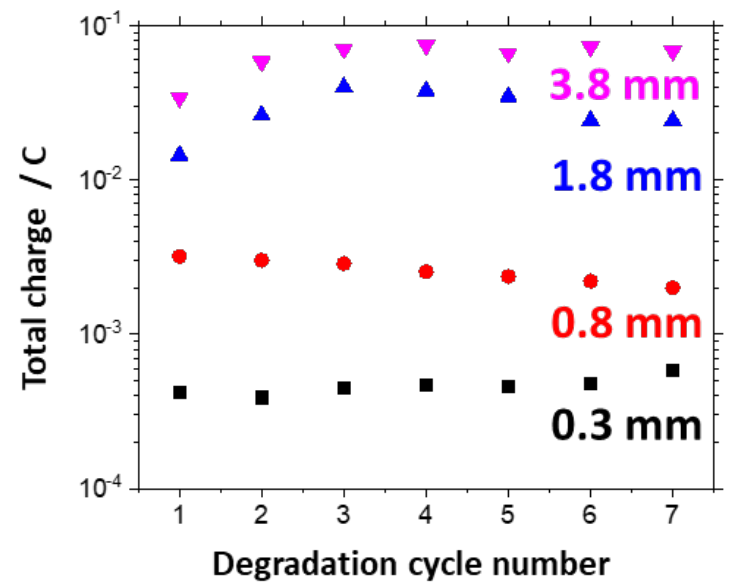

c)

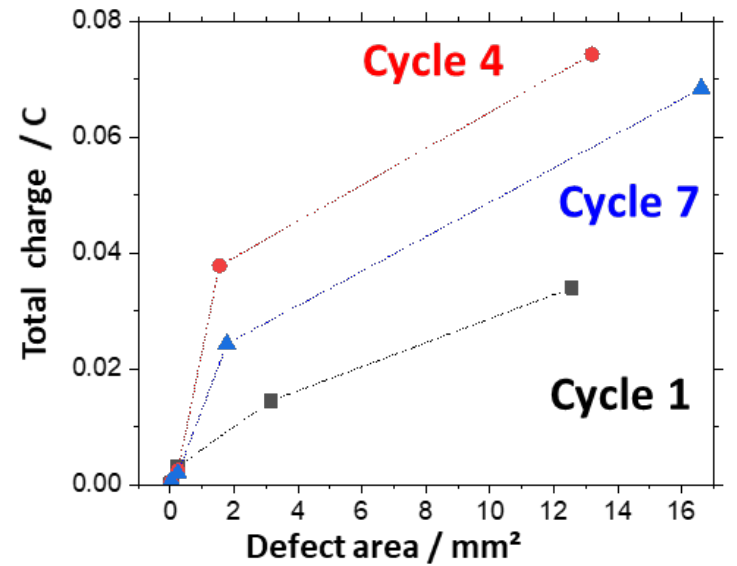

b)

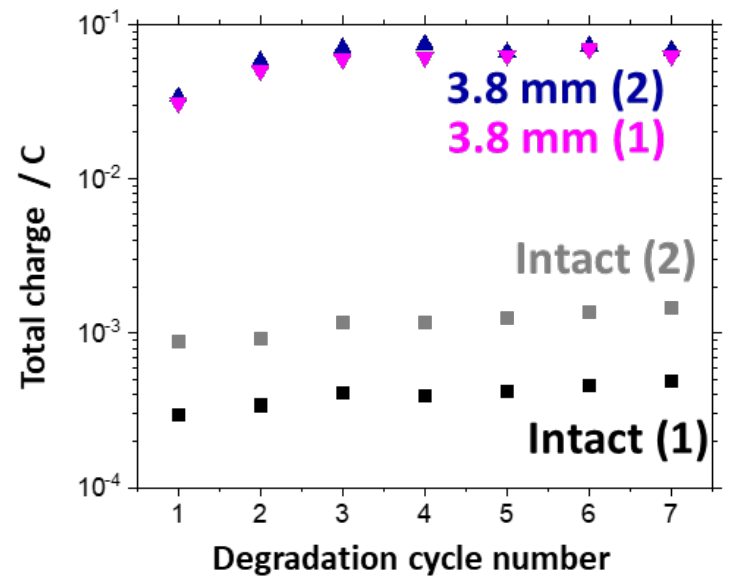

Degradation cycle number

4

5

6

7 

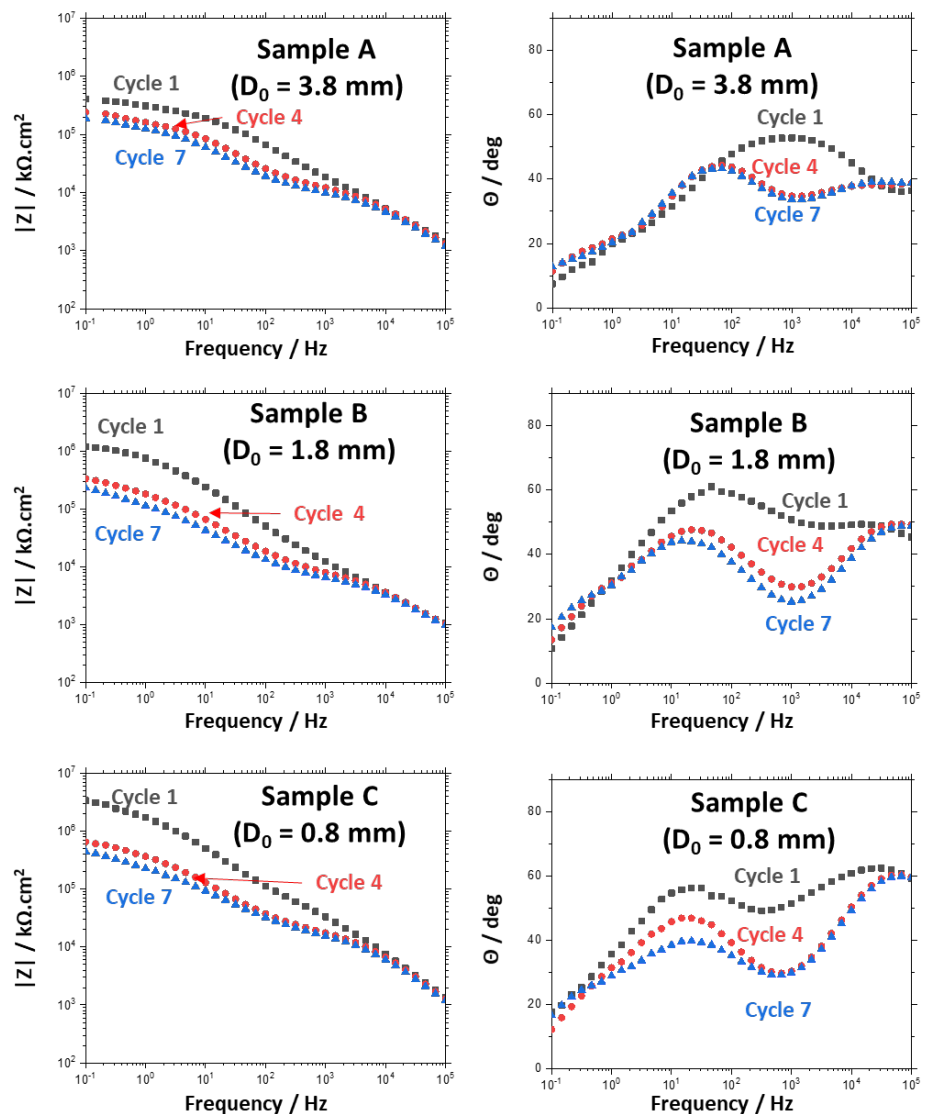

3
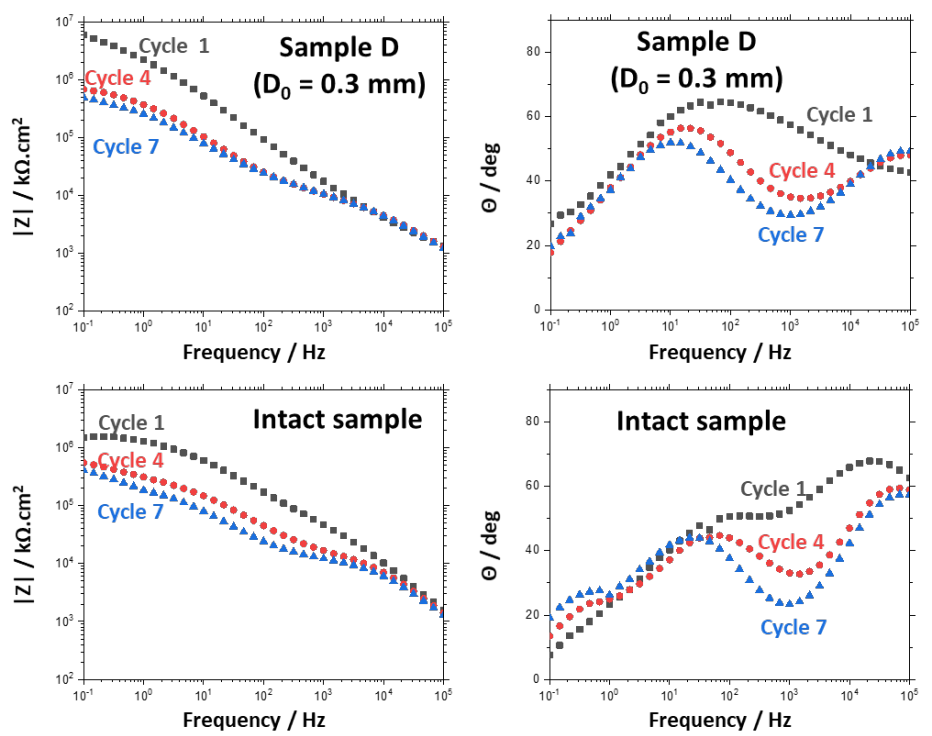
1

2

3

4

Figure 8

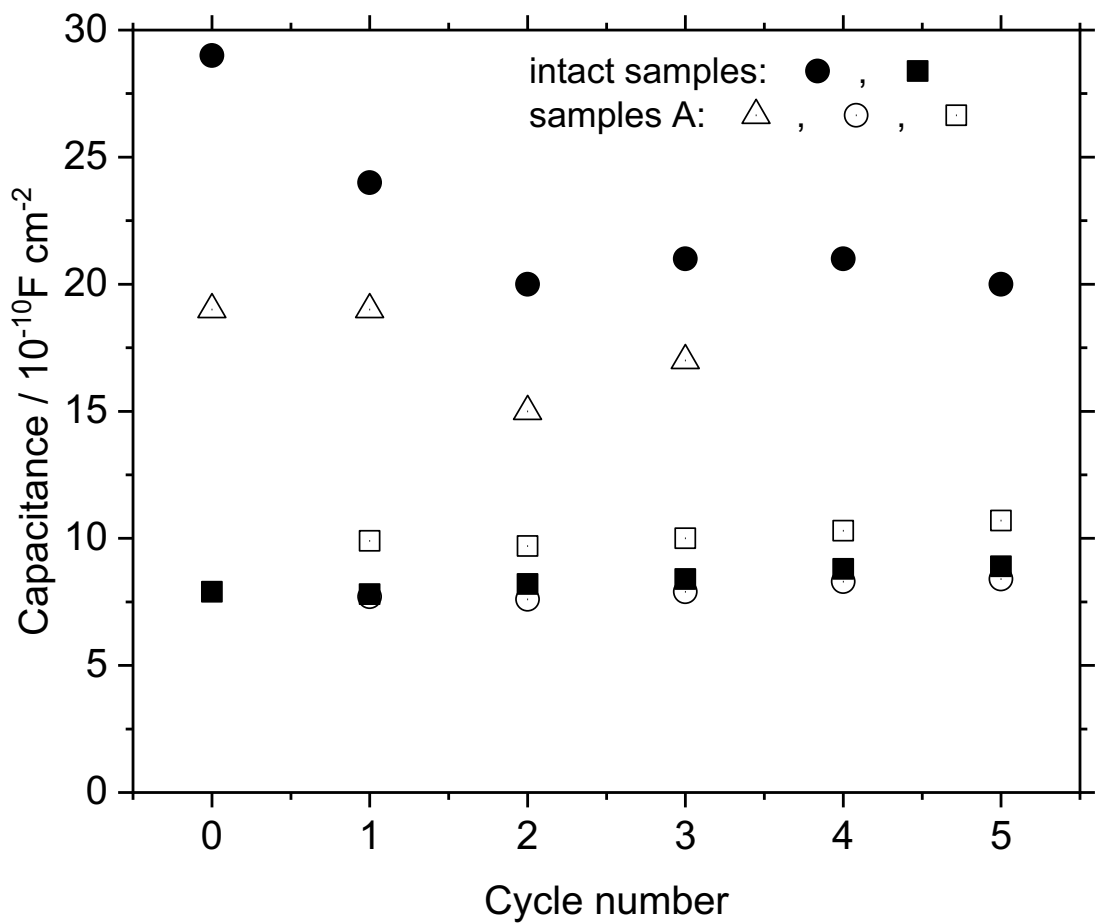

5

6

7

8

9

10

11

12

13

14

15

16

17

18

19

20

21

22

23 
Cycle 1

Cycle 4
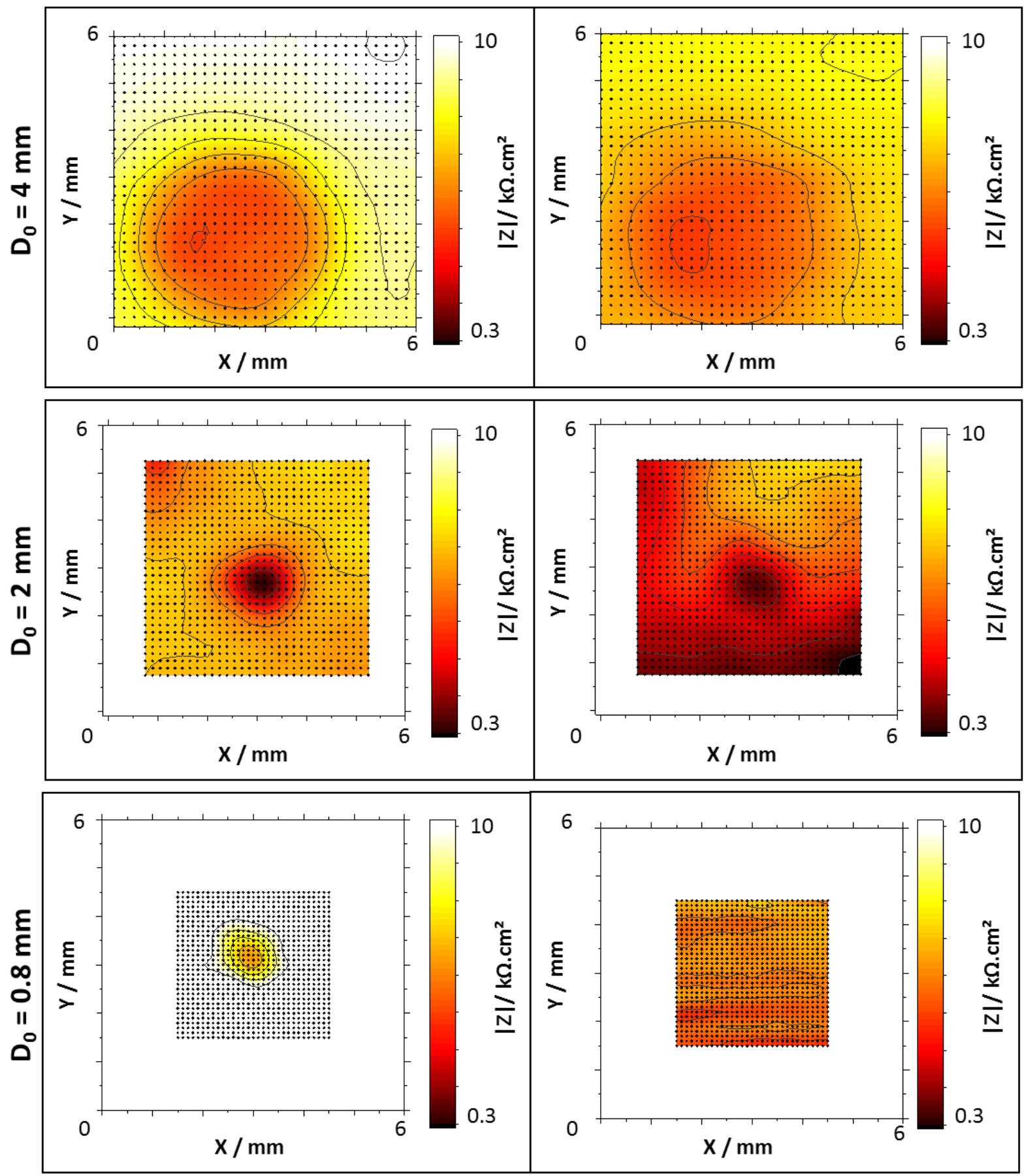
Figure 10.

Cycle 1

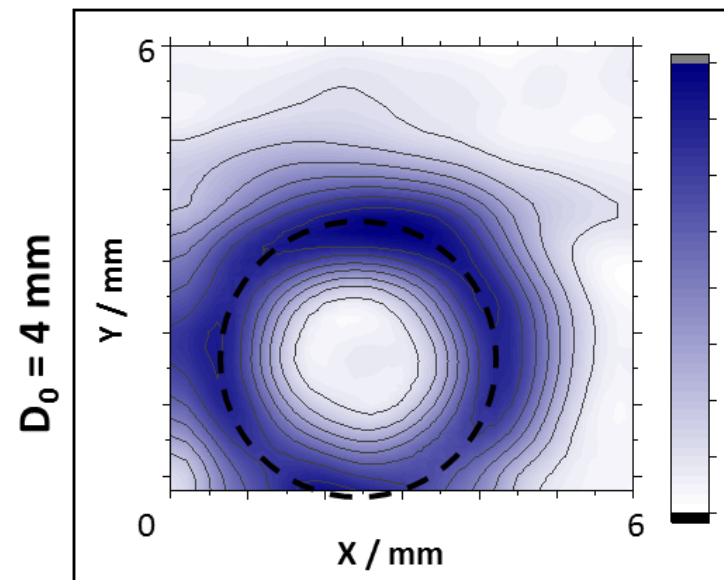

Cycle 4

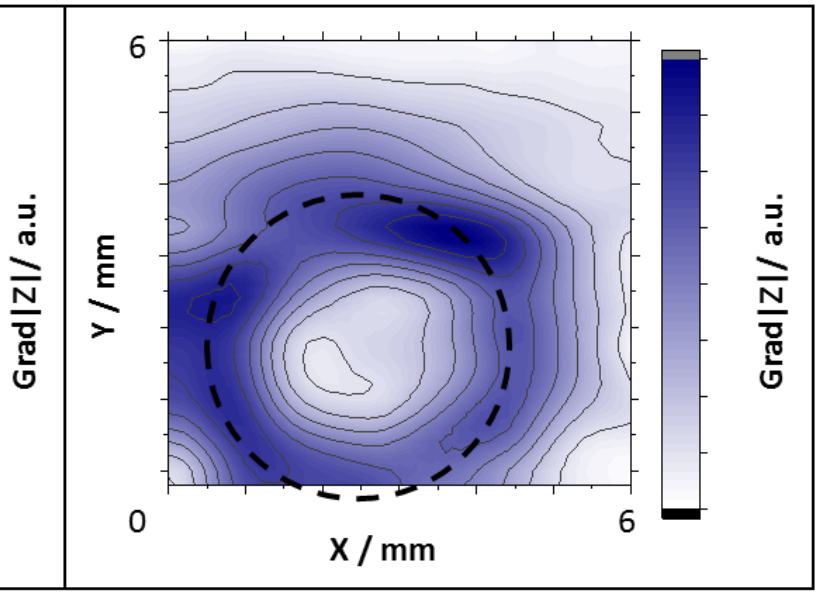

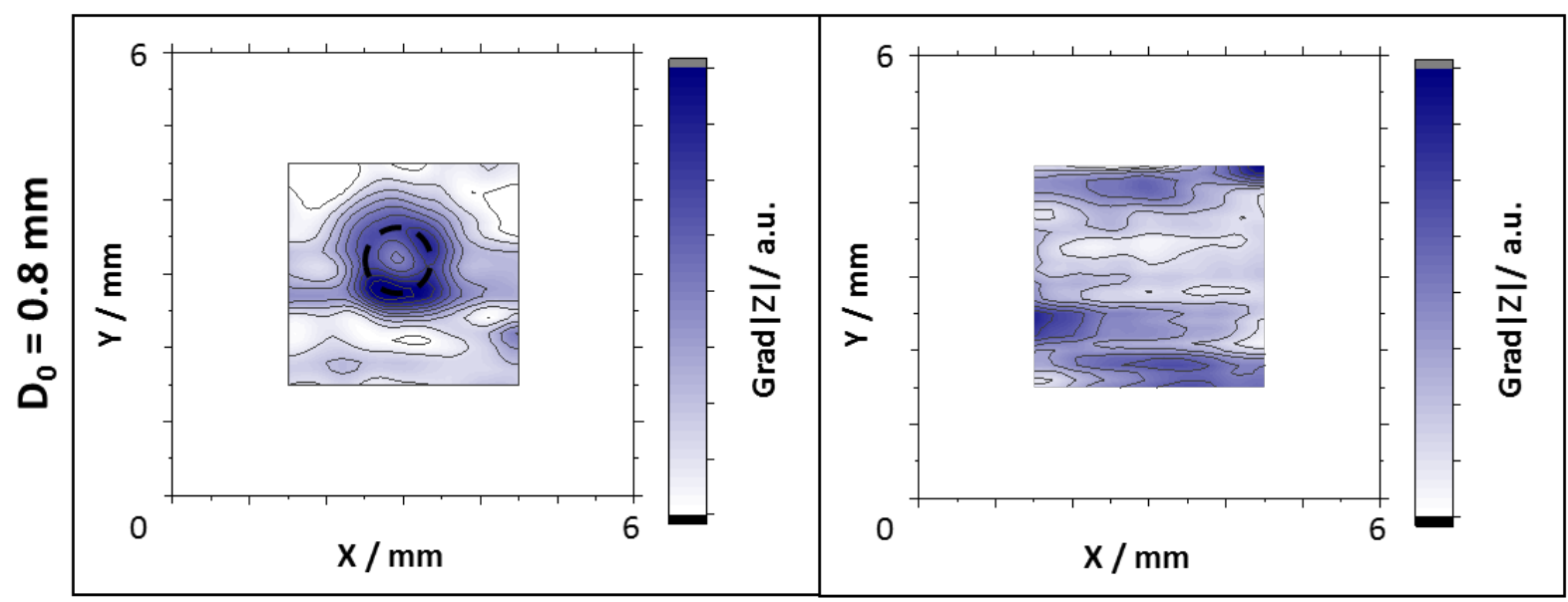

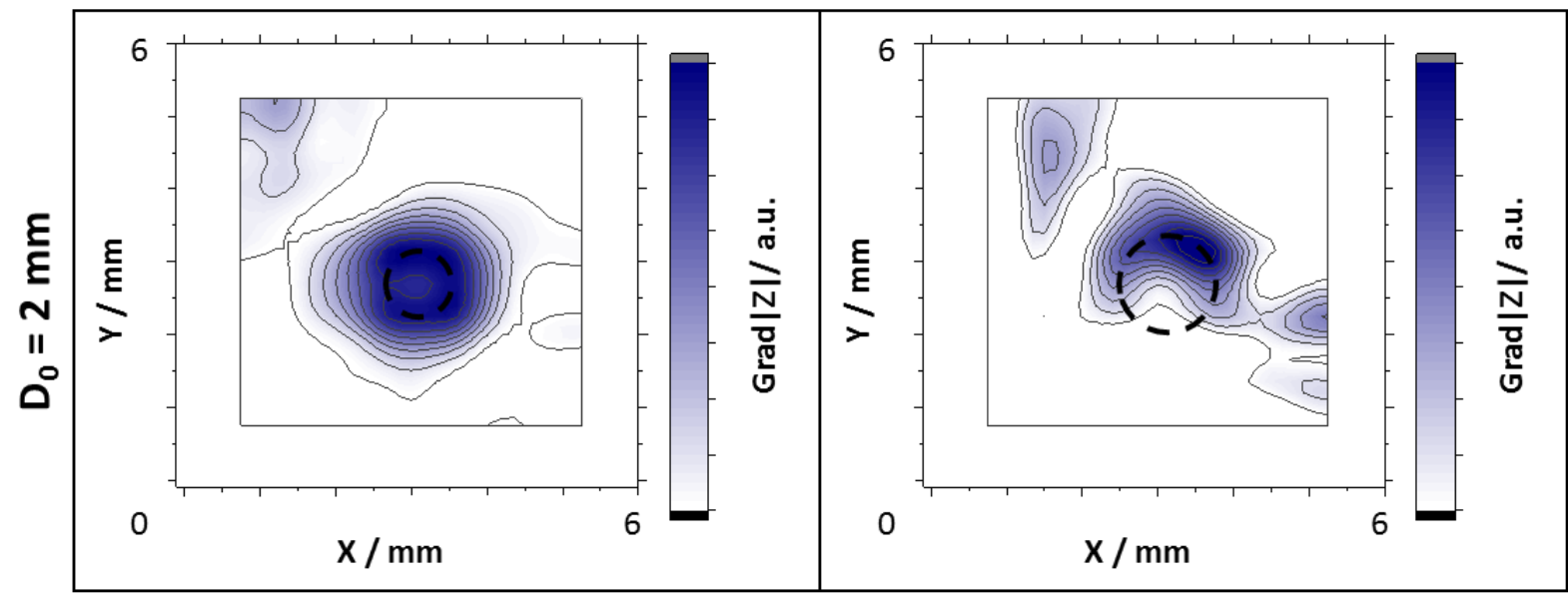


1

2

3

4

Figure 11.

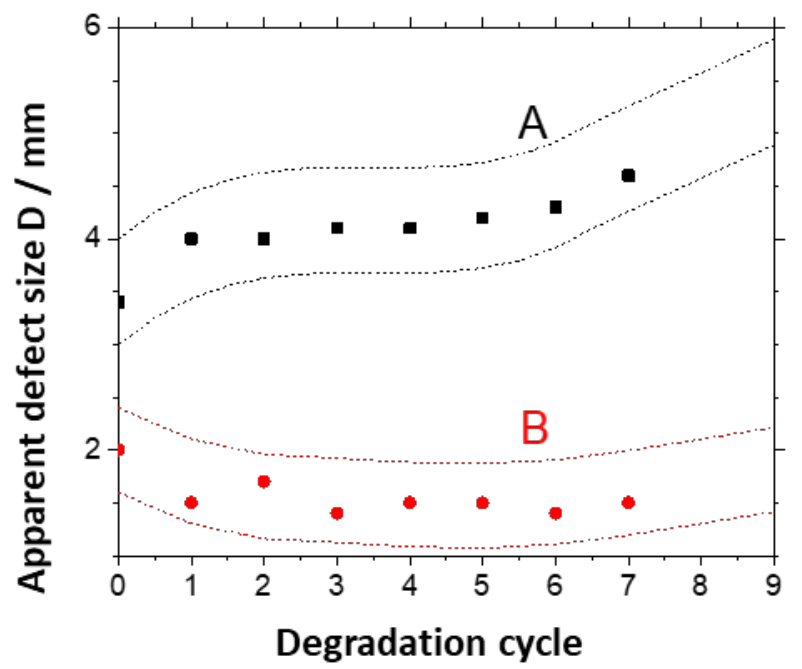

5

6

7

8

9

10

11

12

13

14

15

16

17

18

19

20

21

22

23

24

25

26

27

28

29 
Figure 12.
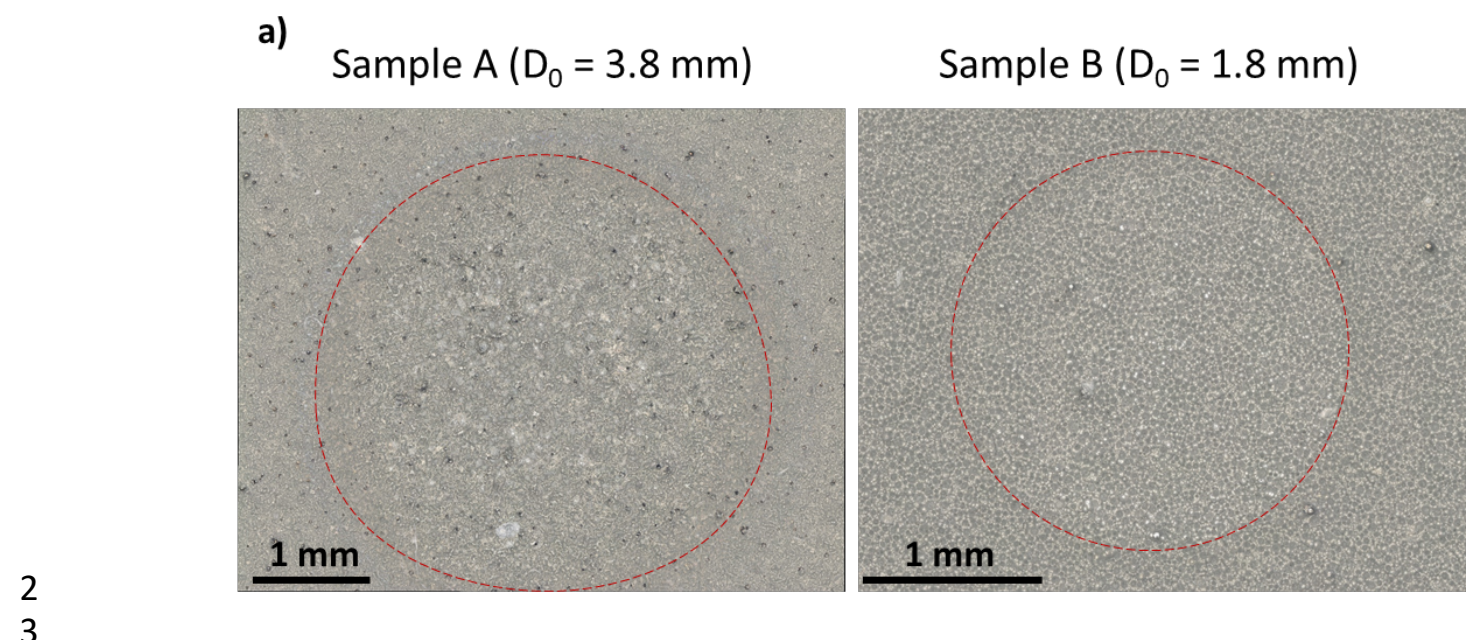

b)
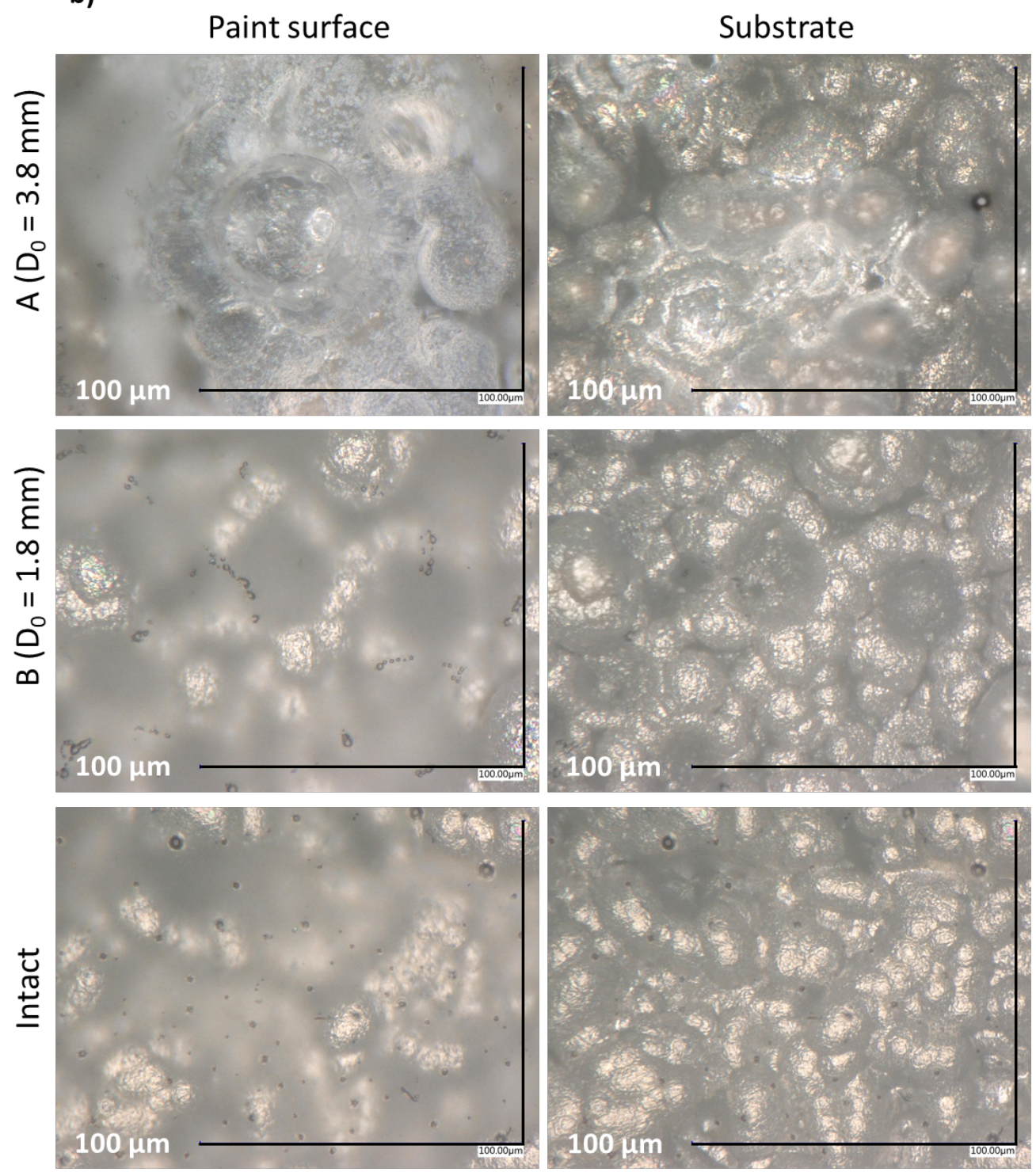